CAHIER DE RECHERCHE \#1808E

WORKING PAPER \#1808E

Département de science économique

Department of Economics

Faculté des sciences sociales

Faculty of Social Sciences

Université d’Ottawa

University of Ottawa

\title{
Institutions, Attitudes and LGBT: Evidence from the Gold Rush*
}

\author{
Abel Brodeur ${ }^{\dagger}$ and Joanne Haddad ${ }^{\ddagger}$
}

June 2018

\footnotetext{
* Special thanks go to Jason Garred and Marc Sangnier. We also thank Francesco Amodio, Vincent Chandler, Marie Connolly, Stefano DellaVigna, Fabien Forge, Pauline Grosjean, Adam Lavecchia, Louis-Philippe Morin and seminar participants at Dalhousie University, Montreal Applied Micro Day, SCSE, SMU and the University of Ottawa for comments and suggestions. Any remaining errors are our own.

${ }^{\dagger}$ Department of Economics, University of Ottawa; 120 University Private, Ottawa, Ontario, Canada, K1N 6N5; e-mail: abrodeur@uottawa.ca

₹ Department of Economics, University of Ottawa; 120 University Private, Ottawa, Ontario, Canada, K1N 6N5; e-mail: jhadd086@uottawa.ca
} 


\begin{abstract}
This paper analyzes the determinants behind the spatial distribution of the LGBT population in the U.S. We relate the size of the present-day LGBT population to the discovery of gold mines during the 19th century gold rushes. Comparing the surroundings of these gold mines to other current and former mining counties, we find that there are currently 10-15\% more same-sex couples in counties in which gold discoveries were made during the gold rushes. We also provide empirical evidence that residents of gold rush counties still have more favorable attitudes toward homosexuality nowadays. Our findings are consistent with two mechanisms. First, gold rushes led to a large (temporary) increase in the male-tofemale ratio. Second, we show that gold rush counties were less likely to house a notable place of worship at the time of the discovery (and in the following decades) and are currently less religious, suggesting a role of institutions in shaping attitudes and norms.
\end{abstract}

Key words: persistence, LGBT, attitudes, institutions, religion.

JEL Classification: O13, O18, J10, R23. 


\section{Introduction}

The geographic distribution of minority groups and attitudes toward these groups vary significantly across and within societies. Many contemporaneous socioeconomic determinants of these differences have been proposed, but few studies have analyzed their origins (e.g., Card et al. (2008); Dustmann and Preston (2001); Dustmann et al. (2011); Edin et al. (2003)).

In this paper, we investigate the role of the California Gold Rush (start date 1848) and other gold rushes (Oregon (1851), Colorado (1858), Washington (1873) and Alaska (1896)) on the current place of residence of the U.S. LGBT population and attitudes toward this group. We provide empirical evidence that the current geographic distribution of the LGBT population is positively related to the gold rushes during the mid-to-late 19th century. We also provide evidence that the gold rushes led to more positive attitudes toward homosexuality which persisted in the long-run.

Identifying the causal effect of historical shocks such as natural resources discoveries on current outcomes is difficult for a number of reasons (Couttenier et al. (2017)). For example, characteristics of mining counties and non-mining counties differ along many dimensions (see Section 4) and economic shocks other than gold discoveries could have happened later. We address these issues by exploiting the year of discovery of gold and by comparing two types of gold mining counties: (1) counties in which gold was discovered during one of the gold rushes (1848-1899) and (2) counties in which gold was discovered before and after the gold rushes (see Figures 1 and 2).

This identification strategy is attractive because the latter group of mining counties is more comparable to gold rush mining counties than nonmining counties. The identification assumption is that gold rush mining counties would have the same number of LGBT individuals as counties in the control group if gold discoveries in these places had happened before or after the gold rushes. This assumption seems reasonable given that the sample of gold rush and non-gold rush mining counties is balanced across a wide range of geographic variables.

The two sets of counties nonetheless differ in two key dimensions. We show that gold discoveries during one of the gold rushes (henceforth "gold rush counties") led to a large (temporary) increase in the male-to-female ratio, whereas other gold discoveries had virtually no impact on sex ratios. Our estimates suggest that gold rush counties had male-to-female ratios of seven on average in the first census after the discovery of gold. This is likely 
due to the fact that gold rush counties were mostly inhabited at the moment of gold discovery and that the gold rushes led to the largest mass migration in the history of the U.S. The other dimension along which gold rush counties differ from other gold mining counties is the quality and existence of local institutions at the time of gold discovery. In order to document the presence of very weak (religious) institutions for gold rush counties, we build a new data set of all notable cathedrals, churches and missions in the U.S. using data from the National Register of Historic Places. We show that only 9 percent of gold rush counties had a notable place of worship at the time of gold discovery in comparison to 44 percent for control counties.

In a first step, we test whether counties with gold rush discoveries currently have more unmarried partner households of the same sex. Our estimates suggest that there are currently 10-15 percent more same-sex couples in gold rush counties than in our control group, i.e., non-gold rush discoveries. These findings are robust to several specification checks such as the inclusion in our model of state fixed effects, geographic controls and controls for the share of foreign born individuals and military bases, as well as the use of another comparison group, i.e., other mineral discoveries (oil or gas resources, copper, iron, nickel or silver) 11 The effects on same-sex unmarried couples for counties neighboring gold rush counties are smaller and less precisely estimated suggesting that the effects are mostly local. However, the estimated effect is amplified for gold rush mining counties that neighbor another gold rush county. Last, we also provide evidence that gold rush counties, in comparison to non-gold rush counties, have more same-sex couples who are married.

As an additional robustness check, we test whether the positive relationship between the gold rushes and the size of the LGBT population is driven by current socioeconomic characteristics and local amenities. We include in our model a broad range of county variables to proxy for demography, economic activity, education and urbanization. (See Section 7 for the exhaustive list of variables.) Adding these variables to our model decreases the correlation between gold rush discoveries and the number of unmarried partner households of the same sex decreases by only a quarter. This suggests that the estimates of the reduced-form relationship are too large to imply that the gold rushes mainly affects the geographic distribution of the LGBT population through current socioeconomic characteristics.

\footnotetext{
${ }_{1}^{1}$ Maurer and Potlogea (2017) examine the impact of male-biased demand shocks arising from oil discoveries in the South of the United States between 1900 and 1940. They find no effect on the female population share and women's labor force participation at the county-level.
} 
In a second step, we test whether individuals currently living in gold rush counties have pro-LGBT attitudes. We rely on data from the General Social Survey (GSS) for the time period 1993-2014 and show that residents in gold rush counties are more likely to report that homosexuality is not wrong than respondents in control counties. ${ }^{2}$ The estimated effect of gold discovery during the gold rushes is quite large and robust to many specification checks including the use of a composite index of many questions related to homosexuality. We also provide evidence that both migrants and non-migrants living in gold rush counties are more likely to report pro-LGBT attitudes. These results suggest that pro-LGBT attitudes have persisted in gold rush counties and that both individuals growing up and moving to gold rush counties have more favorable attitudes toward this group.

These results are intriguing given that we are directly comparing gold rush and non-gold rush counties. Both set of counties are mostly located in the West, have similar geographical characteristics and have had balanced sex ratios for more than 100 years. It thus remains unclear why gold rush counties still have higher levels of pro-LGBT attitudes 150 years after the initial shock. We provide suggestive evidence that the differential in attitudes is partly driven by the lack of (local) formal institutions at the moment of gold discovery and in the following decades. Using data from the National Register of Historic Places, we show that 9 percent of gold rush counties had a place of worship at the time of gold discovery and that 42 percent still do not have a notable place of worship. For the remaining 49 percent of gold-rush counties, it took on average about 30 years from gold discovery to build a notable place of worship. We also confirm that residents of gold rush counties are still less likely to be fundamentalist using GSS data. Overall, our findings suggest that gold rush mining counties were subject to continued weak religious institutions which helped pro-LGBT attitudes and the high concentration of the LGBT population to persist.

We make three important contributions in our paper. First, to our knowledge, we are the first paper to empirically document the origins of the spatial distribution of the LGBT population in the United States. Second, we provide suggestive evidence on historical determinants of divergence in current attitudes regarding homosexuality ${ }^{3}$ Finally, we provide evidence

\footnotetext{
${ }^{2}$ In the GSS, the proportion of respondents who think that sexual relations between two adults of the same sex are not wrong at all ranges between 27 percent in Riverside county, California and 83 percent in Yolo county, California.

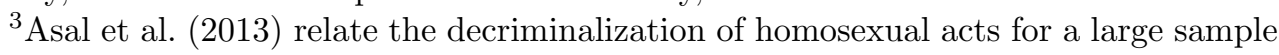


that the initial institutional environment plays an important role in shaping social norms and attitudes in the short- and long-run Acemoglu et al. (2001); Banerjee and Iyer (2005); Buggle and Durante (2017); Couttenier et al. (2017); Dell et al. (Forthcoming); Grosjean (2014)).4

Our work contributes to a literature that studies the persistent effects of historical shocks on the spatial distribution of population (e.g., Ahlfeldt et al. (2015)), economic activity (e.g., Bleakley and Lin (2012); Davis and Weinstein (2002); Miguel and Roland (2011); Redding et al. (2011)) and gender roles (e.g., Alesina et al. (2013)). Our results also add to a growing literature on the persistence of attitudes, culture and norms (e.g., Bazzi et al. (2017); Brodeur et al. (Forthcoming); Fernández and Fogli (2009); Nunn and Wantchekon (2011); Voigtländer and Voth (2012)). Our findings are relevant given the importance of culture, social norms and attitudes for economic development (Algan and Cahuc (2010); Fafchamps (2006); Knack and Keefer (1997); Nunn and Wantchekon (2011); Tabellini (2008b); Tabellini (2008a)).

Our findings also relate to papers analyzing the consequences of disequilibria in sex ratios (e.g., Abramitzky et al. (2011); Angrist (2002); Carranza (2014); Hesketh and Xing (2006); Schacht and Kramer (2016); Teso (Forthcoming) ). 5 Baranov et al. (2018) and Grosjean and Khattar (Forthcoming) analyze the short- and long run effects of the large numbers of male convicts and far fewer female convicts sent to Australia in the 18th and 19th centuries. They provide evidence that people living in areas that were historically more male-biased were more likely to vote against same-sex marriage and have more conservative attitudes toward women working $!^{6}$ We provide a discussion in Sections 2 and 8 on the divergence of our results from these papers. We point out the contextual setting and selective migration as likely explanations.

Last, our paper contributes to a small literature on the economics of LGBT. Previous studies have analyzed homosexual/heterosexual earnings

of countries to variables such as legal origin, religion and economic development. This study only shows partial correlations and does not tackle endogeneity issues and omitted variable bias.

${ }^{4}$ We contribute to a recent literature on the long-term effects of mineral discoveries (e.g., Barone and Mocetti (2014); Buonanno et al. (2015)). Couttenier et al. (2017) document that historical mineral discoveries in the U.S. are positively associated with current homicides and assaults in counties in which the discoveries occurred before formal institutions were established.

${ }^{5}$ Many papers examine the determinants of gender imbalance. See Anderson and Ray (2010) and Edlund and Lee (2009) for example.

"Chang (2015) finds that contemporaneous male-to-female ratios are negatively correlated with the likelihood of revoking state sodomy laws. 
and labor supply differences (Allegretto and Arthur (2001); Antecol and Steinberger (2013); Black et al. (2003); Blandford (2003)), hiring and workplace discrimination (Weichselbaumer (2003); Aksoy et al. (2018)) and antigay sentiment (Andersen and Fetner (2008); Coffman et al. (2016)). Black et al. (2007) provide a literature review and Black et al. (2000) discuss data sources. Recent contributions document the spatial distribution of LGBT population (e.g., Black et al. (2002); Gates (2013); Smart and Whittemore (2017)) and revealed attitudes toward homosexuals using average home prices (Christafore et al. (2013)).

The remainder of this paper is structured as follows. In section 2, we offer a brief historical overview of the gold rushes and a conceptual framework. Section 3 details the data sets and provides descriptive statistics. Section 4 presents the methodology and the model specifications. In Section 5, we document initial conditions in gold rush counties. Section 6 presents the results on the current spatial distribution of the LGBT population and attitudes toward this group. Section 7 provides a discussion of our main findings and empirical evidence that the gold rushes may have affected the size of the LGBT population through the quality and existence of religious institutions. The last section briefly concludes.

\section{Background}

\subsection{Brief History of the Gold Rushes}

The discovery of gold on January 24, 1848, by James Marshall led to the largest gold rush in American history. It took most of 1848 for word to leak out. Rumors were later confirmed on December 5, 1848 by President James Polk in his State of the Union address. News about the California Gold Rush resulted in the largest mass migration in American history producing a swift demographic change. Overland or by ship, hundreds of thousands of migrant workers ("forty-niners") set off to California.

Shortly after the discovery of gold in California, the Josephine Creek discovery in 1851 by a group of miners originally from Illinois set in motion Oregon's Gold Rush. Following Josephine Creek's gold discovery, new discoveries were made following the rush of prospectors into Southern Oregon. For instance, significant gold discoveries occurred at Sailor Diggins and Althouse Creek in Illinois Valley in 1852. The Rogue Indian War and the Fraser River gold discovery in Canada marked the end of Oregon's gold rush in the 1860s. 
Pike's Peak region of the Kansas and Nebraska Territories also witnessed a gold rush which lasted between 1858 and 1861, the Colorado Gold Rush. The Swauk Creek gold discovery in 1873 marked the only significant gold rush in the State of Washington. The deposits were depleted by early 1880's marking the end of the Washington gold rush. Montana's Gold Rush era lasted for a few years during the 1860-70s.

Alaska's Gold Rush dates back to 1896 when George Carmack and Skookum Jim discovered gold on Bonanza Creek. Between 1898 and 1899 gold was discovered in Nome, Alaska, launching what is referred to as the Nome Gold Rush.

Migration and Male-to-Female Ratio A number of characteristics make the gold rushes different than other mineral discoveries. First, the gold rushes attracted hundreds of thousands of young men to the West. The mass migration of men to areas where gold was discovered resulted in a large increase in population and temporarily unbalanced sex ratios in gold rush counties.

The most dramatic example may be the California Gold Rush. Clay and Jones (2008) document that about 2-3 percent of all native-born men aged 20-40 in the U.S. were residing in California by the end of 1850.7 Men from Mexico, Canada, the United Kingdom and mainland Europe also migrated to gold rush counties. California's population increased from 8,000 Californios $^{8}$ at the end of the 1840 s to 120,000 in 1850 (U.S. California Census) $9^{9}$ This increase was mostly driven by the influx of about 110,000 male gold rushers. By 1852, California's population increased to 200,000. Women constituted only $8 \%$ of the Californian population in 1850 . This percentage increased to 30 percent by $1860($ Holliday $(2015)) \cdot{ }^{10}$

The other gold rushes had a similar (temporary) effect on the male-tofemale ratio. For instance, population in Alaska nearly doubled following the Alaska Gold Rush with about 64,000 inhabitants, out of which 46,000 were males and 18,000 females Nugent (2007). We confirm this pattern of

\footnotetext{
${ }^{7}$ Factors positively related to migration to California include age, literacy and distance to California (Clay and Jones (2008)).

${ }^{8}$ A Californio was a Spanish speaking, Catholic person of Latin American descent born in Alta California between 1769 and 1848. Alta California is the area that roughly corresponds to modern-day California.

${ }^{9}$ The 1850 Census was subject to a number of criticisms including the loss of data for Contra Costa, Santa Clara and San Francisco counties and the fact that not everyone in California was enumerated. California, which became the 31st official state in 1850, made another official count in the 1852 California Census.

${ }^{10}$ This decrease in the male-to-female ratio resulted from the immigration of families and births in California, as well as the immigration of single females (Hurtado (1999)).
} 
unbalanced sex ratios in gold rush counties in Appendix Figures A8 and A9. These figures illustrate sex ratios in 1860, 1870 and 1960 across U.S. counties. Sex ratios in the West were imbalanced during the 1860-70s, whereas counties in the South and Northeast regions had more balanced sex ratios. In contrast, sex ratios were nearly balanced across all counties in more recent years (see Appendix Figure A10,11 We formally test in Section 5 that only gold rush discoveries led to temporarily unbalanced sex ratios.

Local Religious Institutions The gold rushes were also different than other mineral discoveries because of the lack of (local) formal institutions. The lack of places of worship was particularly evident. Goodrich (1859) writes that "Away from law, away from public opinion, away from the restraints of home [...] puritan became a gambler; the boy taught to consider dancing a sin soon found his way to masked balls; monte became as familiar as the communion, and the catechism was forgotten, while the champagne popped sparked and excited."

Using historical data on Baptist, Congregational, Methodist, Presbyterian and Roman Catholic churches, Maffly-Kipp (1994) documents that there were twice as many churches per capita in New York and Ohio than in California in 1860. In Iowa, a frontier region that was settled and evangelized during the same years as California, there were three times more churches per capita than in California. Maffly-Kipp (1994) writes that "Gold rush California has consequently been depicted as a society without religion-'a prehistory'." We further investigate in Sections 5 and 7 whether gold rush counties were subject to weak (local) religious institutions and whether individuals in these counties are currently less likely to be religious.

\subsection{Gold Rushes and the LGBT Population}

Historical records indicate more favorable attitudes regarding homosexuality in gold rush mining areas. During the 19th century, LGBT population lived in hiding to avoid persecution. Sodomy was a felony in all states and considered capital a offense in some states. The lack of formal institutions in gold rush counties made it easier for LGBT individuals to avoid oppression and discrimination. With very weak religious institutions at the time, sexual relations between men were not as socially opposed as in the rest

\footnotetext{
${ }^{11}$ Appendix Figure A11 reports sex ratios for all counties for the time period 18202010. Sex ratios are close to one for most counties before and after the gold rushes. In contrast, sex ratios are male-biased in many counties during the gold rushes time period.
} 
of the country. Hurtado (1999) argues that what was otherwise damned as immoral, was not completely removed from gold rush societies. This seemed designed to satisfy the appetites of a population of young men.

The lack of religious institutions and punishment may have favored pro-LGBT attitudes in gold rush counties. Men miners worked and lived together in mining camps. William (1999) writes that miners "lived cheekby-jowl with one another, even sharing beds and blankets." Many historians highlight the fact that men miners were fulfilling traditional women's role like cooking and housekeeping. Men accepted to become dancing partners of other men (Boyd (2003)). See Appendix Figures A1 and A2. At nights men were "identified" to have accepted to take a woman's part by either tying scarves around their arms or wearing a patch on a certain part of their expressibles (Lipsky (2006)). In some camps, better dressed men would be identified as those willing to be dancing partners of other men. Lipsky writes that "The people of the gold rush understood sexuality differently than they do today. Concepts of homosexuality, bisexuality and heterosexuality had not yet been invented, so people did not define themselves by their sexual orientation. Having intimate relations with a person of the same gender did not automatically make anyone into 'a certain kind' of individual."

While it may have been a matter of convenience for some migrants to move to these male abundant gold rush areas, some of the migrant men may have been homosexuals who seized this economic opportunity to move West at a time where norms where almost absent. Lipsky (2006) writes that "With few women in the city and even fewer in the mining camps, men undoubtedly turned to each other for comfort of all kinds. For some, in their physical and sexual primes, it may have been a matter of convenience only, but others certainly seized the opportunity to live exactly as they pleased, far from home and free of traditional social pressures.' 12

\subsection{Persistence and Transmission of Attitudes}

Many economics papers provide evidence that historical shocks may persist via culture and norms (Couttenier et al. (2017); Guiso et al. (2006); Tabellini (2008a)). Attitudes, culture and norms may be transmitted hor-

\footnotetext{
${ }^{12}$ While large male-to-female ratios in mining camps could have led to the development of the sex industry (Brodeur et al. (Forthcoming)), historical letters and diaries suggest that the small number of commercial sex workers led to very high sex act prices in mining camps (William (1999)). Lipsky (2006) reports that sex act prices ranged from $\$ 200$ to $\$ 400$ a night $(\$ 4,000$ to $\$ 8,000$ in 2005 dollars). Miners and clerks could thus not afford these services.
} 
izontally and vertically (Giuliano and Nunn (2017)). This is important in our context given that experimental findings and self-reported data suggest that increased contact with persons known to be homosexuals increases tolerance and acceptance toward the LGBT population (e.g., Altemeyer (2002)).

Bisin and Verdier (2011) reviews models of cultural transmission and explain that beliefs and culture are partly transmitted through generations and acquired by different forms of learning. Importantly, the initial conditions in some of these models determine the long-run equilibrium 13 This is important in our context given the lack of (or the presence of weak) religious institutions. If formal enforcement is weak, then individuals may be more likely to transmit pro-LGBT values and attitudes to other generations (Tabellini (2008a)).

We argue that the lack of formal religious institutions shaped cultural norms and attitudes in gold rush counties. Weak institutions and attitudes persisted and reinforced one another over time.

Pro-LGBT attitudes in gold rush counties may be linked to the likelihood for LGBT individuals to self-identify and self-disclose their sexual orientation and through selective migration to these counties. In other words, locational preferences could be a function of LGBT attitudes and formal enforcement in the area (Yue (2013)). A rich literature on migrants also point out that locational decisions are linked to the size of the minority group already in that location (e.g., Munshi (2003)). Expectations about future income, labor discrimination and persecution may explain this relationship 14

To sum up, the gold rushes could have a persistent effect on the size of the LGBT population through the transmission of pro-LGBT values and migration of homosexuals. The lack of formal religious institutions at the time of gold discovery may have determined the long-term equilibrium in gold rush counties through the formation of local institutions and attitudes.

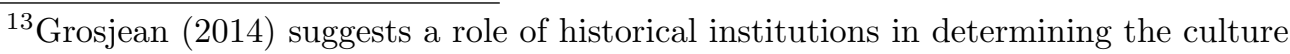
of violence transmitted to subsequent generations in the South of the U.S.

${ }^{14}$ Using Census data, Black et al. (2007) show that gay male partners and lesbian partners are less likely to be living in their state of birth than heterosexual couples. In 2000, about 22 percent of gay male partners were both living in their state of birth (Black et al. (2007)). This number goes up to 39 percent for heterosexual couples. These figures reflect the very high mobility of the LGBT population.
} 


\section{Data Sources}

\subsection{LGBT Data}

In order to construct the size of the LGBT population at the county level, we use decennial census data. The 2010 U.S. census identifies same-sex cohabiting couples based on information about the sex of the members of the household and information from the relationship question. The Census Bureau designates as the head of household (or householder) "the member (or one of the members) in whose name the home is owned, being bought, or rented." Then data are collected on all household members, with each person being identified in terms of her or his relationship to the householder. Our measure of unmarried partnered households is thus based on households of the same sex reporting an unmarried partnership. In 2010, there were 2.2 unmarried partner households of the same sex per 1,000 inhabitants, and about 515,000 unmarried partner households of the same sex. Figure 3 displays the number of unmarried partner households of the same sex per capita in 2010. This map illustrates that San Francisco, Seattle and Oakland are some of the (large) cities with the highest number of same-sex couples per inhabitants ${ }^{15}$

As a preview of our main results, three out of the 15 counties with the highest number of unmarried partner of the same sex per capita are gold rush counties 16

We also use data from the American Community Survey (ACS) for the years 2013-2016. The ACS data is available at the Public Use Microdata Areas (PUMA) level. PUMAs are nested within states and contain at least 100,000 people. In 2016, about 3.3 percent of respondents reported being in a same-sex married couple. Of note, though, our research focuses on a time period in which the number of same-sex married couples was growing. There were 2.3 percent of same-sex married couples in the U.S. in 2013 in comparison to 4 percent in 2016. This is likely due to the rapid expansion of states legalizing same-sex marriage and to the ruling of the Supreme Court in the civil rights case of Obergefell v. Hodges.

Note that we examine a subset of the LGBT population: same-sex co-

\footnotetext{
${ }^{15}$ We compute using 2010 Census data that about 20 percent of same-sex couples were residing in only 15 counties.

${ }^{16}$ Note that San Francisco county is also in the top 15, but is not a gold rush county. This is due to the fact that there were no gold discovery in this county. For this reason, our main estimates are likely underestimating the effect of the gold rushes on the size of the LGBT population.
} 
habiting couples who describe their relationship as "unmarried partnership" and same-sex cohabiting married couples. Census data at the county level is unfortunately not available for gay men and lesbians not in a cohabiting relationship (Carpenter and Gates (2008)). ${ }^{17}$ Nonetheless, we believe that census data is informative on the whole LGBT population due to the high correlation of this measure with other surveys. Using Census data and selfreported data from Gallup's Daily Tracking survey, Gates (2015) show that the geographic patterns of same-sex couples and adults self-identifying as LGBT are similar. For instance, three metropolitan statistical areas are in the top five of the 1990 Census same-sex couple rankings and the Gallup rankings. Moreover, Carpenter and Gates (2008) compare individual level surveys (California's 2003 Lesbian, Gay, Bisexual, and Transgender Tobacco Survey and California Health Interview Survey (CHIS)) data and 2000 Census data. They find that the Census 2000 sample is very similar across a variety of demographic characteristics to both the CHIS and Tobacco Survey 18

Last, the spatial distribution of LGBT in the Census and ACS is similar to the data compiled by Fisher et al. (Forthcoming). In their paper, they provide estimates of the population of married same-sex tax filers for the years 2013-2014. They estimate that 0.35 of all joint filers were same-sex couples in 2014. Appendix Figure A3 illustrates the spatial distribution of married same-sex tax filers using their data. The data is available at the 3-digit ZIP code. Among the 100 largest commuting zones, San Francisco and Santa Rosa (California) had the highest rate of same-sex couples in married filing jointly returns in 2014 .

\subsection{Mineral Resources Data}

The Mineral Resources Data System (MRDS) provides information on all mineral discoveries in the United States. For the purpose of this paper, we keep only mineral discoveries for which the information on the exact geographic location and year of discovery is available. We use a variable generated by MRDS, "primary commodities," that reflects commodities that might be economically viable as the only commodity. Our sample com-

\footnotetext{
${ }^{17}$ Carpenter and Gates $(2008)$ provide estimates on the number of gay men and lesbians not in a cohabiting relationship. They find that more than half of gay men and a third of lesbians were not cohabiting.

${ }^{18}$ Carpenter and Gates (2008) document that gay and lesbian couples living in California are 39 years old on average. About 5 percent of gay and lesbian couples are Black, non-Hispanic, and 15 are Hispanic. Approximately 18 percent had a high school diploma or less.
} 
prises all different categories of development status defined by the MRDS: occurrence, prospect, producer, past producer and plant ${ }^{19}$

The year and location of discovery enables us to categorize gold discoveries as part of a gold rush or not. Gold discoveries are deposits that include gold, exclusively or among other minerals, as a primary commodity. Our data set includes 4,086 gold deposits discovered between 1700 and 2000 across 26 states.

We construct a variable GoldRushes that is equal to one for a county if at least one gold discovery occurred during one of the gold rushes and zero otherwise. We define the gold rushes as discoveries that occurred between the years 1848-1899 in the Pacific and Mountain divisions, i.e., Western region. We also include the few discoveries in South Dakota during that time period. There are 321 counties in the U.S. with at least one gold discovery during the period 1700-2000. Of these, 211 are codified as gold rush counties. Figure 1 illustrates all gold rush discoveries in the U.S. (See Appendix Figure A4 for discoveries in Alaska. 20 These figures confirm that there were many discoveries in Colorado, Montana, Northern California, Sierra Nevada, etc. Figure 2 shows the other gold counties, i.e., gold mining counties without a gold rush discovery.

\subsection{Churches and Other Places of Worship}

We use the National Register of Historic Places (NRHP) to create a database on notable cathedrals, churches and missions. NRHP provides information on the United States historic places deemed worthy of preservation. It categorizes five types of properties: district, site, structure, building, or object. This database includes data on more than one million property out of which 80,000 are individually listed and the rest are contributing resources within historic districts.

\section{Identification Strategy}

In this section, we first show that gold rush counties differ from other counties. We then provide evidence that the sample of mining counties during the gold rushes (treated group) and non-gold rush mining counties

\footnotetext{
${ }^{19}$ Note that our main conclusions are robust to the use of only deposits for which the status is producer or past producer. Results available upon request.

${ }^{20}$ Appendix Figures A5, A6 and A7 provide illustrations of gold rush discoveries for the time periods 1848-1859, 1860-1869 and 1870-1899.
} 
(comparison group) is balanced across a wide range of covariates. Last, we describe the main specifications and the controls.

\subsection{Predict the Location of Gold Rush Discoveries}

We evaluate whether the location of counties with gold rush discoveries is related to observable characteristics in Table 1. The unit of observation is a county. Columns 1 and 2 show the results from linear probability models that consider many observable characteristics simultaneously. The dependent variable is the dummy GoldRushes and we include all U.S. counties in the analysis. The objective is to predict whether a county had gold discoveries during one of the gold rushes (1848-1899). We include in both columns division fixed effects and the following geographic variables: latitude, longitude, the natural log of total land area, mean and standard deviation of elevation, distance to the state's capital and a dummy for coastal counties. We also include the natural log of population in 2010, the percentage of foreign born in 2010 and a dummy for the presence of military bases. In column 2, we add contemporaneous county variables such as the natural log of median personal income and median house value of owner-occupied housing units, an ethno-linguistic fractionalization index, the unemployment rate, the urbanization rate and the percentage of residents who graduated high school.

The results suggest that gold rush discoveries are related to observable characteristics. In column 1, three variables out of 10 are statistically significant at conventional levels. For instance, gold rush discoveries are negatively associated with distance to the capital of the state. When considering the set of geographic variables jointly, the joint $p$-value is about 0.002 (excluding division dummies). In column 2, five out of the 18 variables included are statistically significant. These results suggest that the location of gold rush mines is not random and can be explained by observable characteristics.

\subsection{Identification Strategy}

Our identification strategy consists in comparing gold rush counties to counterfactual counties. In our main empirical specification, we compare gold rush counties to a set of gold mining counties in which gold was not discovered during one of the gold rushes. The key identification assumption is that the year and location of gold discoveries is exogenous conditional on observables. The main concern is the omitted-variable bias. Gold rush 
counties could be in locations that have unobservable characteristics that are associated with the presence of the LGBT population. We investigate in Table 1, columns 3 and 4, whether observable characteristics at the county-level predict whether a gold mining county is a gold rush county or not. We thus restrict the sample to counties with gold discoveries and directly compare gold rush and non-gold rush mining counties.

The specification in column 3 is the same as in column 1. Similarly, column 4 includes the same controls as in column 2. In column 3 , none of the ten variables is statistically significant at the 10 percent level. In column 4, only two variables are significantly (at the 10 percent level) related to whether the county is a gold rush county: urbanization and unemployment rate. When considering the set of geographic variables jointly, the joint $p$ value is about 0.41. Our findings suggest that the sample of gold rush and non-gold rush mining counties is balanced across a wide range of covariates and that the identification assumption is credible. In the empirical analysis, we include division or state fixed effects and the geographic variables to relax the identification assumption.

\subsection{Model Specifications}

The objective is to investigate the impact of the gold rushes. To identify this effect, we rely on the following empirical models. ${ }^{21}$

Basic Specification We first rely on a basic model comparing counties that experienced a gold rush to other counties controlling for covariates susceptible to affect the location of gold mines and the spatial distribution of the LGBT population.

Our baseline equation is:

$$
Y_{c s}=\alpha+\beta \text { GoldRushes }_{c}+\lambda \text { NotGoldRushes }_{c}+X_{c}^{\prime} \zeta+\delta_{s}+\varepsilon_{c s},
$$

where $Y_{c s}$ is the natural log of one plus the number of unmarried partner households of the same sex in county $c$ and state $s$ in 2010. GoldRushes, our variable of interest, is a dummy indicating whether the county experienced a gold rush during the years 1848-1899. $\delta_{s}$ are state fixed effects and $X_{c}^{\prime}$ is a set of control variables at the county level. We control for

\footnotetext{
${ }^{21}$ As a robustness check, we exploit the increase in the male-to-female ratio in gold rush counties and directly analyze the effect of the maximum male-to-female ratio on the size of the LGBT population. In this framework, we first instrument the maximum male-to-female ratio for the time period 1820-2000 using as an instrumental variable GoldRushes. The empirical model and the estimates are presented in the Appendix.
} 
a number of county exogenous controls including latitude, longitude, land area in miles, mean elevation, standard deviation of elevation, oil or gas resources existence, distance from the county to the state capital, and lastly whether or not it is a coastal county. We also control for the natural log of population. In some specifications, we further control for a set of (endogenous) contemporary controls to proxy for demography, economic activity, education and urbanization. We cluster standard errors at the state level.

Since our identification strategy relies on the comparison between gold rush mining counties and non-gold rush mining counties, we construct a dummy, NotGoldRushes, indicating whether a county had at least one gold discovery either before or after the gold rushes time period ${ }^{22}$ This dummy is also equal to one for gold discoveries in the East during the years 1848-1899. We include this placebo treatment in equation 1 to show that non-gold rush discoveries are usually not related to the current size of the LGBT population.

Differences-in-Differences The previous specification does not directly compare gold rushes and non-gold rushes mining counties. We rely on another model that relies on non-gold rush mining counties as a direct comparison group. We estimate the following specification using a differencein-difference approach:

$$
Y_{c s}=\alpha+\gamma \text { Gold }_{c}+\phi \text { Gold } \times \text { GoldRushes }_{c}+X_{c}^{\prime} \zeta+\delta_{s}+\varepsilon_{c s}
$$

where $\phi$ denotes the coefficient of the interaction term between Gold $_{c}$, a dummy equal to one if gold was discovered in county $c$ and zero otherwise, and GoldRushes, , a dummy equal to one if gold was discovered in county $c$ between 1848 and 1899 and zero otherwise. $\gamma$ captures the average relation between gold discoveries and the natural log of unmarried partner households of the same sex, whereas $\phi$ reports whether the effect is different whether or not discoveries occurred during one of the gold rushes.

Our results hinge on the assumption of quasi-random variation in the relative timings of gold discovery and place of discovery, conditional on a set of observable characteristics.

\footnotetext{
${ }^{22}$ There were also gold discoveries in the East during the years 1848-1899. We include these discoveries in the control group. Note that excluding these gold discoveries has no effect on our main conclusions.
} 


\section{$5 \quad$ Historical Environment}

In this section, we show that our treated an control groups differ in two key dimensions. We first confirm that the gold rushes temporarily increased sex ratios. We then provide evidence that most gold rush counties did not have formal religious institutions at the time of gold discovery.

\subsection{Male-to-Female Ratio}

We estimate the effect of the gold rushes on male-to-female ratios in Table 2. The equation is:

$$
\text { MFRatio }_{c d}=\alpha+\beta \text { GoldRushes }_{c d-10}+\delta_{c}+\gamma_{d}+\varepsilon_{c d},
$$

where $M F$ Ratio $_{c d}$ is the male-to-female ratio in county $c$ and decade $d$. GoldRushes $_{c d-10}$ is a dummy variable that assumes the value of one for county-decade observations with the earliest gold rush discovery during the 10 years preceding a decennial census and zero otherwise. Gold rush counties are counties with at least one gold discovery during one of the gold rushes (1848-1899). County and decade fixed effects are included in the model. $\beta$ thus captures the average relation between the first gold discovery and the male-to-female ratio in the next decennial census for gold rush counties. The time period for this analysis is 1820-2000.

The estimate in column 1 suggests that the male-to-female ratio increases by about 5.8 following a gold discovery during one of the gold rushes. Our estimate is statistically significant at the 1 percent level. The mean of the dependent variable is about 1.1 suggesting that there were 7 men for each women on average in gold rush counties. In columns 2 and 3 , we also include in the model two variables capturing the medium- and long-term effect of the gold rushes on the male-to-female ratio. The estimates suggest that the male-to-female ratio was approximately 1.5 (1.0) 10 to 20 years (20 to 30 years) after the first gold rush discovery. These results suggest that unbalanced sex ratios in gold rush counties did not last.

As a comparison group, we rely on non-gold rush discoveries. We present the estimates in column 4 . We find no evidence that non-gold rush discoveries had a positive impact in the short-, medium- and long-run on the male-to-female ratio in these localities. The estimates are all very small and negative and range from -0.01 to -0.07 . These results are consistent with the idea that only gold rush discoveries led to a mass migration of men and that gold rush counties were virtually inhabited at the moment of 
the first gold discovery. In other words, non-gold rush discoveries occurred in counties already populated by single men, women and families.

Our results are robust to alternative definitions of the variable GoldRushes. For example, we show that subsequent gold discoveries in gold rush counties, i.e., after the first gold discovery, also increased the male-to-female sex ratio, but to a lesser extent (see Appendix Table A1).

\subsection{Places of Worship During the Gold Rushes}

We now provide empirical evidence that gold rush counties were subject to weak religious institutions in comparison to the control group using a novel data set of notable cathedrals, churches and missions (see Section 3). We provide two pieces of evidence that individuals in gold rush counties were subject to weak religious institutions. We first plot the share of gold mining counties with at least one notable place of worship by decade. As shown in Figure 4, the percentage of gold mining counties with at least one notable place of worship at the time of gold discovery is much lower during the gold rushes (1848-1899) than during any other decade for the time period 1830-2000. For example, about 10 percent of counties with at least one gold discovery during the 1860s had a place of worship. In contrast, the share of gold mining counties pre- and post-gold rushes with a notable place of worship was over 40 percent.

Second, we check whether gold rush counties were less likely to have a notable place of worship at the time of (the first) gold discovery. We find that only 9 percent of gold rush counties had a notable place of worship at the time of gold discovery. This is in stark contrast to gold mining counties without gold rush discoveries. For this group, about 44 percent had a notable place of worship at the time of gold discovery. As a robustness check, we compute the percentage of non-gold rush counties with a gold discovery prior to 1900 that had a notable place of worship. Similarly, we find that approximately 37 percent of these counties had a notable place of worship.

We formally test whether gold rush counties were less likely to have a notable place of worship at the time of gold discovery than other gold mining counties in Table 3. We present estimates of equation (1) in which the dependent variable is a dummy that takes the value of one for counties with a notable place of worship at the time of (the first) gold discovery and zero for counties without a notable place of worship at the time of discovery. We rely on probit estimation and report marginal effects. We 
restrict our sample to counties with at least one gold discovery at any time. We thus directly compare gold rush counties to non-gold rush counties.

The estimated relationship between having a notable place of worship at the time of gold discovery and being a gold rush mining county is negative and statistically significant at the 1 percent level. The estimate in column 1 suggests that gold rush counties were about 35 percent less likely to have a notable place of worship. Adding our set of county exogenous controls (columns 2-5) and region (column 3), division (column 4) or state fixed effects (column 5) has no effect on the magnitude and significance of our estimates 23

Overall, our results confirm that gold rush counties and control counties differ along two dimensions: temporarily unbalanced sex ratios and the presence of very weak (local) religious institutions.

\section{Present-Day Outcomes}

In this section, we describe the relationship between the gold rushes and the current spatial distribution of the LGBT population. We use data on unmarried partner households and same-sex married couples. We also present a set of robustness checks to validate our main estimates. Last, we test whether present-day attitudes toward the LGBT population are more favorable in gold rush counties using the General Social Survey.

\subsection{Basic Results: LGBT Population}

The results derived from estimating equation (1) are reported in Table 4 . The dependent variable is the natural log of one plus the number of unmarried partner households of the same sex in 2010. What clearly emerges is that counties with at least one gold discovery during the gold rushes time period, i.e., 1848-1899, currently have statistically significantly more unmarried partner households of the same sex than other counties. In column 1, we include only the natural log of population in 2010 . The estimated relationship between the number of unmarried partner households of the same sex and being a gold rush mining county is positive and statistically significant at the 2 percent level. The estimate suggests that there

\footnotetext{
${ }^{23}$ We present further robustness checks in Appendix Table A2. For instance, we show that our estimates are robust to adding to the model additional controls such as an indicator for whether or not counties had other mineral discoveries, the percentage of foreign born and a dummy for whether or not the county is hosting a U.S military base.
} 
are about 14 percent more unmarried partner households of the same sex in 2010 in gold rush mining counties than in other counties.

In column 2, we add an indicator for whether there was at least one gold discovery in the county either before or after the gold rushes time period. This dummy serves as our first "placebo" treatment. The point estimate is small and statistically insignificant. We test and confirm that the estimated effect of the gold rushes is larger than the effect for this additional variable.

In column 3, we include all our exogenous controls in the model: latitude, longitude, total land area, mean and standard deviation of elevation, distance to the state's capital and a dummy for coastal counties. The estimate for gold rush counties (coeff. 0.175, std. error 0.045) is now larger and significant at the 1 percent level, while the estimated coefficient for our "placebo" treatment remains small and statistically insignificant.

Columns 4, 5 and 6 add to the model respectively region, division and state fixed effects. Adding state fixed effects to the model helps us to control for state policies and anti-discrimination laws. The point estimates range is stable around 0.12 , suggesting that there are 12 percent more unmarried partner households of the same sex in gold rush mining counties. The estimates are all statistically significant at the 2 percent level. By contrast, the estimates for counties with gold discoveries before or after the gold rushes are now negative and statistically significant in two specifications out of three.

Appendix Table A3 explores a different measure of intensity for the gold rushes: the number of gold discoveries during the gold rushes (18481899). See Appendix Figure A12. There are approximately 8 (std. dev. 11) gold rush discoveries on average for counties with at least one gold rush discovery. The structure of the table is the same as Table 4. As we can see, the estimated coefficients of gold rushes intensity are positive and statistically significant in all columns. In contrast, the evidence presented suggests that the number of gold discoveries before or after the gold rushes is not related to the number of unmarried partner households of the same sex. The estimates are all very small and statistically insignificant.

\subsection{Differences-in-Differences: LGBT Population}

One concern with the previous estimates is that they do not directly compare gold rushes and non-gold rushes mining counties. Table 5 reports the results of equation (2), where we implement our differences-in-differences approach. Column 1 first shows the relationship between being a gold min- 
ing county and the number of unmarried partner households of the same sex. In column 2, we include the variable GoldRushes interacted with the gold mining dummy. We then progressively add control variables and fixed effects in the remaining columns as in Table 4.

In all regressions, the coefficient of interest, $\phi$, is positive and the estimated coefficients range from 0.080 to 0.177 . The estimates are statistically significant at conventional levels in five our of six regressions. (Statistically significant at the 12 percent level in column 5.) This means that counties with at least one gold discovery which occurred during one of the gold rushes in the West currently have approximately 10-15 percent more unmarried partner households of the same sex.

\subsection{Robustness Checks}

We test the sensitivity of our results to the choice of covariates, the definition of our control group and the way we compute our standard errors in Table 6 and Appendix Tables A4 and A5. Table 6 presents estimates of equation 2. (See Appendix Table A6 for estimates of equation 1.) In columns $1-5$, we include our full set of exogenous controls and state fixed effects. In column 1, we add a variable for other mineral discoveries. This serves as a placebo treatment and as an additional control. The variable "Other Minerals" equals one for counties with discoveries of either copper, iron, oil or gas resources, nickel or silver and zero otherwise. The point estimate is very small and statistically insignificant. The estimated effect of the gold rushes is significantly larger than the effect for the variable "Other Minerals." This result is in line with the idea that other mineral discoveries did not lead to large male-to-female ratios and occurred in many areas with existing institutions. For instance, Maurer and Potlogea (2017) find that oil discoveries in Texas, Louisiana, and Oklahoma during the time period 1900-1940 had no effect on oil county sex ratios.

Columns 2 and 3 include controls for the percentage of foreign born and a dummy for whether the county is housing a U.S. military base. ${ }^{24}$ Arguably, military bases may lead to male biased sex ratios. In column 4, we include these additional controls simultaneously. The point estimates are virtually the same as in Table 5, column 6, confirming the robustness

\footnotetext{
${ }^{24} \mathrm{We}$ collect information on U.S. military bases from this website https:// militarybases.com/. The military base variable is equal to one if there is an air force, army, coast guard, marine corps, navy or joint operations military bases and zero otherwise. Including dummies for the different categories of military bases has no effect on our main conclusions. About seven percent of counties have at least one military base.
} 
of our results. Last, we test whether our estimates are similar if we keep only counties in the West, i.e., we drop counties in the other three Census regions. Restricting the sample to the West slightly increases the size of our coefficient of interest and its corresponding $t$-statistic.

We show that our findings are also robust to alternative definitions for our main comparison group in Appendix Table A4. Our estimates are robust to the exclusion of gold discoveries before the gold rushes (column 1), during the years 1848-1899, but in the Eastern and Southern regions (column 2), during the years 1900-1950 (column 3) and since 1950 (column 4). For example, in column 1, Gold is now equal to zero for gold discoveries before the gold rushes. The estimates presented in these four columns are all positive, statistically significant and of similar magnitudes than in Table 5. column 6 .

In Appendix Table A5, we use the estimation method developed by Conley $(1999,2008)$ to take into account spatial correlation (Hsiang $(2010))$. In columns $1-2$, standard errors are adjusted for spatial correlation within a $100-\mathrm{km}$ radius. Columns 3-4 report standard errors adjusted for spatial correlation within a $300 \mathrm{~km}$ radius. In columns $5-6$, we rely on a $500-\mathrm{km}$ radius. Standard errors are slightly smaller than for the corresponding columns (5-6) of Table 4 .

So far, our findings suggest that there are currently more unmarried partner households of the same sex in counties (within a state) in which gold was discovered during one of the gold rushes. We now test whether there are currently more same-sex married couples in these areas. We rely on ACS data for the years 2013-16. In our sample, the mean of the variable "Same-Sex Married Couples" is 3.3 per 1,000 inhabitant.

Appendix Table A7 presents estimates of equation (2) where the dependent variable is the natural log of one plus the number of same-sex married couples. The analysis is at the PUMA level and we thus have 2,346 observations. In the specifications without region, division or state fixed effects, the estimates are large, positive, significant at the 2 percent level and range from 22 to 33 percent. In contrast, the estimates are much smaller (coeff. 0.106 and std. err. 0.069) and statistically significant solely at the 14 percent when we include state fixed effects. These results suggest that same-sex married couples are much more likely to be living in goldrush counties and more generally in Western states. But we provide only weak evidence that the gold rushes are related to the number of same-sex married couples when we compare counties within a region or a state. 


\subsection{Neighbor}

Table 7 explores another measure of intensity: neighboring a county with at least one gold discoveries during the gold rushes. ${ }^{25}$ In column 1, we show that counties neighboring a gold rush county do not have significantly more unmarried partner households of the same sex than other counties in the U.S. The coefficient is positive, but not statistically significant.

In columns 2-6, we interact our variable GoldRushes ${ }_{c}$ with an indicator for whether the county is neighboring a gold rush county. The interaction is positive and statistically significant at conventional levels in most specifications. The estimates range from 0.10 to 0.30 , suggesting that gold rush counties neighboring another gold rush county have approximately 10 to 30 percent more unmarried partner households of the same sex. These results suggest that the long-run effects of the gold rushes are somewhat local, but amplifies when many neighboring counties had gold discoveries.

\subsection{Socioeconomic Characteristics}

The association between gold discoveries in the West during the mid-late 19th century and the number of same-sex couples may reflect positive income shocks on local economies that would have lasted until nowadays. We test in Table 8 and Appendix Table A8 whether local amenities and socioeconomic characteristics may explain the current geographic distribution of the LGBT population in gold rush and non-gold rush mining counties. Table 8 presents estimates of equation 2, whereas Appendix Table A8 reports estimates of equation 1. In column 1, as a baseline, we report estimate for our specification with exogenous controls and state fixed effects. Column 2 adds to our model the percentage of black or African American and an ethno-linguistic fractionalization index in 2010 to take into account differences in partnership status and homosexuality approval by race (Black et al. (2007); Christafore et al. (2013)). In column 3, we control for the county unemployment rate, the natural log of median personal income and the percentage of families below the poverty level in 2010 as proxies for economic activity. Column 4 adds controls for urbanization (the natural log of median house value of owner-occupied housing units, the percentage

${ }^{25}$ We estimate the following specification:

$$
Y_{c s}=\alpha+\beta \text { GoldRushes }_{c}+\mu \text { GoldRushes } \times \text { Neighbor }_{c}+X_{c}^{\prime} \zeta+\delta_{s}+\varepsilon_{c s},
$$

where $Y_{c s}$ is the natural log of one plus the number of unmarried partner households of the same sex in county $c$ in 2010. The variable Neighbor $_{c}$ is equal to one if the county neighbors a county for which GoldRushes ${ }_{c}$ is equal to one. 
of units with a value of less than $\$ 100,000$, the percentage of units with a value of more than $\$ 500,000$, population density and the urbanization rate) to capture location preferences of homosexual and heterosexual individuals (Black et al. (2002); Black et al. (2007); Smart and Whittemore (2017); Stephan and McMullin (1982)). In column 5, we control for the percentage of high school graduate. Column 6 includes all these additional controls simultaneously. Appendix Table A9 report the estimates for these controls 26

As apparent in columns 2, 3 and 5, controlling for the racial composition, the local economic environment and educational attainment in 2010 does not alter the estimate. In other words, including these controls does not affect the size and significance of our coefficient of interest for equations 1 and 2. By contrast, the correlation between gold rush and the number of unmarried partner households of the same sex decreases by about a quarter when controlling for urbanization in 2010. In column 6, when all the controls are included simultaneously, our estimates also decrease in size by about a quarter and are statistically significant at the 2 percent level for equation 1 and at the 11 percent level for equation 2. Two possible interpretations of these findings are that the gold rush had a persistent effect on urbanization and/or increased the size of the LGBT population, thereby leading to an increase in housing prices and urbanization.

To sum up, our estimates suggest that the persistence in the geographical distribution of LGBT population is partly explained by urbanization. But most of the long term effect of gold rushes is not explained by current socioeconomic characteristics.

\subsection{Attitudes Regarding Homosexuality}

In this subsection, we present the results on the impact of the gold rushes on current attitudes regarding homosexuality. We rely on data from the General Social Survey (GSS) over the years 1993-201427 and focus on the following question: "What about sexual relations between two adults of the same sex-do you think it is always wrong, almost always wrong, wrong only sometimes, or not wrong at all?" Answers to this question are somewhat polarized. About 55 percent of respondents report that it is always wrong,

\footnotetext{
${ }^{26}$ We find a positive and statistically significant association between the number of unmarried partner households of the same sex and the median personal income, the median house value of owner-occupied housing units, the ethno-linguistic fractionalization index and educational attainment.

${ }^{27}$ The GSS geographic identification code files are available only since 1993.
} 
whereas a third of the respondents report it is not wrong at all 28

The model is similar to equation (2) with the exception that the unit of observation is now the individual. We also control for the individual's demographic characteristics. Specifically, we estimate:

$$
Y_{i c s t}=\alpha+\gamma \text { Gold }_{c}+\phi \text { Gold } \times \text { GoldRushes }_{c}+X_{c}^{\prime} \zeta+Z_{i t}^{\prime} \theta+\delta_{s}+\varepsilon_{i c s t}
$$

where $Y_{i c s t}$ is the answer to the question of whether sexual relations between two adults of the same sex is always wrong, almost always wrong, wrong only sometimes, or not wrong at all for individual $i$ in county $c$, state $s$ and year $t$. We rely on ordered probit response models where the dependent variable is discrete and defined on a finite ordinal scale. $Z_{i t}^{\prime}$ is a vector of individual characteristics. These characteristics include the individual's gender, age, age squared, six education dummies, three race dummies and five marital status dummies. $X_{c}^{\prime}$ include our set of county exogenous controls 29

Table 9 shows the results from ordered probit regressions. See Appendix Table A10 for the estimates of the individual control variables ${ }^{30}$ The structure of Table 9 is quite similar to Table 5. We control for respondents' characteristics in columns $3-6$ and include our set of exogenous controls in columns 4-6. We include division fixed effects in column 5 and state fixed effects in column 6 . The estimates are all positive and statistically significant suggesting that the gold rushes had a persistent (positive) effect on attitudes toward homosexuality.

One way to gauge the size of our estimates is to standardize the dependent variable for all respondents (within each year) to have a mean of zero and a standard deviation of one. We then run OLS regressions using equation 5. Our estimates suggest that respondents in counties with gold discoveries during one of the gold rushes are about 10 to 25 percent of a standard deviation more likely to report that sexual relations between two

\footnotetext{
${ }^{28}$ Worthen (2012) points out that many studies relate attitudes toward the LGBT population to the beliefs about sexuality, whether it is a "choice" or whether there exists a "gay gene." Attitudes regarding homosexuals are more favorable for those who think that homosexuality is imputed by genetics whereas attitudes regarding LGBT are less favorable for those who think that homosexuality is a choice (Altemeyer (2002); Hegarty and Pratto (2001)).

${ }^{29}$ The GSS includes a sexual orientation question since 2008. About 1.7 percent of respondents report being homosexual and 2.1 percent report being bisexual. We unfortunately cannot use this information in our analysis because of the small sample size.

${ }^{30}$ Females and educated individuals tend to be more likely to report pro-LGBT attitudes. Black or African Americans and other races (in comparison to white respondents) are less likely to report pro-LGBT attitudes.
} 
adults of the same sex is not wrong. Another way to gauge the size of the effect is to contrast it with control variables. For instance, the estimated effect of the gold rushes is about half of the coefficient of graduating college in comparison to having a high school diploma and approximately the size of being a women (in comparison to men).

We test in Appendix Table A11 whether the results on pro-LGBT attitudes are driven by individuals who grew up in gold rush counties or by migrants who are now living in these counties. To answer this question, we restrict the sample respectively to respondents who are living in the same city since the age of 16 (columns 1-3) and to individuals who moved to a different state or city since the age of 16 . The estimates are all positive and statistically significant, suggesting that both migrants and individuals growing up in gold rush counties are more likely report pro-LGBT attitudes. (The estimates are slightly larger for non-migrants.) These findings provide suggestive evidence that pro-LGBT attitudes have persisted through migration and intergenerational transmission.

As a robustness check, we analyze the effect of the gold rushes on other questions concerning attitudes toward LGBT. We create a pro-LGBT index using answers to the question of whether sexual relations between two adults of the same sex is wrong or not and the following three questions: "A man admits to be homosexual: should he be allowed to make a speech in your community?", "A man admits to be homosexual: should he be allowed to teach in a college or university?" and "If some people in your community suggested that a book he wrote in favor of homosexuality, should it be taken out of your public library?" We code the variables as dummies. They are equal to one if respondents report "allowed/not removed" and zero if they report "not allowed/removed" to the last three questions. We also create a dummy for the question of whether sexual relations between two adults of the same sex is not wrong. The dummy is equal to one if the respondents report that it is "not wrong at all" and zero otherwise.

We use these four dummies to create the pro-LGBT index. The index is equal to the sum of the four dummies. For instance, the index takes the value zero if respondents reported that it is "always wrong," "almost always wrong" or "wrong only sometimes" to the first question and answered "not allowed/removed" to the last three questions. Approximately 11 percent of respondents have a score of zero. In contrast, the index takes the value four if respondents answered "not wrong at all" to the first question and "allowed/not removed" to the last three questions. About 31 percent of respondents have a value of four. The mean of this index is 2.7 (std. dev. 
1.27). Our estimates are presented in Appendix Tables A12. The estimates are all positive and of similar sizes than the estimates in Table 9.

To sum up, we find that gold rushes had persistent effects on pro-LGBT attitudes. Our results are consistent with the historic accounts of the gold rushes describing pro-LGBT attitudes. These findings could explain the positive relationship between the number of same-sex couples and gold rush discoveries for two reasons. First, LGBT individuals could migrate to gold rush counties because of the local population's pro-LGBT attitudes or because of the thickness of the LGBT marriage market. We confirm in Appendix Figure A13 that respondents living in counties with more samesex couples are more likely to report pro-LGBT attitudes. This figure plots the relationship between unmarried partner households of the same sex per capita and the percentage of respondents reporting "Not wrong at all" at the county level. The relationship is positive and has a concave shape. Second, pro-LGBT attitudes could be related to the likelihood to self-disclose one's sexual orientation or gender identity.

\section{Possible Channels of Causality}

In this section, we provide a discussion of our main findings and provide suggestive evidence that the lack of local religious institutions in gold rush counties may partly explain the short- and long-term effects of the gold rushes on the geographic distribution of the LGBT population. We then test whether current attitudes in gold rush counties are more liberal in general or only toward the LGBT population.

\subsection{Discussion}

Before testing empirically whether gold rush counties had formal religious institutions in the decades following gold discovery, we situate our main results in the literature.

A growing literature investigates the long-term impact of temporary imbalanced sex ratios. Two recent papers are Bazzi et al. (2017) and Baranov et al. (2018). Baranov et al. (2018) analyze the impacts of the large number of male convicts sent to Australia in the 18th and 19th centuries. They provide evidence that areas receiving more male convicts are now more likely to vote against same-sex marriage. Bazzi et al. (2017) study whether the American frontier fostered individualism. They provide evidence that frontier populations tended to have more prime-age male adults 
and foreign-born. They then show that U.S. counties that were at the frontier for a longer period of time are currently more likely to oppose redistribution and to support the Republican Party.

It may thus seem surprising, at first glance, that the gold rushes led to temporary unbalanced sex ratios and to more positive attitudes toward homosexuality which persisted until today. We argue that the disparity in long-term outcomes could be partly due to the institutional setting. In Australia, homosexuality was heavily repressed under Victorian norms and would be very negatively connoted, as perhaps associated with convictism ${ }^{31}$ Gold rush counties were also different than other frontier regions. For instance, states such as Iowa were "successfully" evangelized, whereas most gold rush counties did not have a notable place of worship at the moment of gold discovery (Maffly-Kipp (1994)).

In what follows, we provide two pieces of evidence that the gold rushes may have affected the size of the LGBT population through the quality and existence of religious institutions. We first test whether gold rush counties had formal religious institutions in the years/decades following gold discovery permitting the transmission of pro-LGBT values. Second, we rely on GSS data to check whether residents of gold rush counties are still less religious than residents of our comparison group.

\subsection{Religiosity Since the Gold Rushes}

We compute the number of years from gold discovery to having at a notable place of worship. Recall that only 9 percent of gold rush counties had a notable place of worship at the time of discovery. We find that about 42 percent of gold rush counties still do not have a notable place of worship in 2000. For the remaining 49 percent, it took on average 28 years before a notable place of worship was built. This figure confirms that residents of gold rush counties were subject to the presence of weak religious institutions in the decades following gold discovery.

We also test whether residents of gold rush counties are currently less fundamentalist using answers to the following question in the GSS: "How fundamentalist is r currently?" where respondents have three choices ( $1=$ Fundamentalist, $2=$ Moderate, and $3=$ Liberal). We present estimates from ordered probit regressions in Table 10. The structure of the table is the same as Table 9. The estimates are all positive and statistically significant at the 1 percent level, confirming that individuals in gold rush counties are less likely to

\footnotetext{
${ }^{31}$ We thank Pauline Grosjean for pointing this out.
} 
be fundamentalist and more likely to be liberal. Our OLS estimates (not shown for space consideration) suggest that the gold rushes decreased by about 10 to 25 percent of a standard deviation self-reported fundamentalism. In another set of regressions, we also provide evidence that respondents in gold rush counties are significantly more likely to report that they never pray. We present the estimates in Appendix Table A13.

Overall, our findings paint a clear picture of religiosity during and following the gold rushes. Individuals living in gold rush counties remained less religious and more tolerant toward the LGBT population up to nowadays, which may be due to the presence of continued weak religious institutions.

\subsection{Other Attitudes}

Our findings suggest that the gold rushes led to pro-LGBT attitudes that persisted until today. But it remains unclear whether attitudes in gold rush counties are more liberal in general or only toward the LGBT population. One the one hand, temporary imbalanced sex ratios and historical mining activity are typically associated with greater opposition to redistribution and economically conservative positions (e.g., Bazzi et al. (2017); Couttenier and Sangnier (2015)). On the other hand, the initial conditions in gold rush counties were different than in other mining counties, with weak religious institutions.

We thus test the effect of the gold rushes on other attitudes and values. We scoured the GSS questionnaires and found four variables covering diverse aspects of traditional American values that were asked repeatedly. The questions are "Please tell me whether or not you think it should be possible for a pregnant woman to obtain a legal abortion if she is married and does not want any more children", "Do you think the use of marijuana should be made legal or not?", "Do you favor or oppose the death penalty for persons convicted of murder?" and "Would you favor or oppose a law which would require a person to obtain a police permit before he or she could buy a gun?" We code the variables as dummies. We also rely on answers to a question in which respondents are asked whether they think of themselves as liberal or conservative. Respondents are offered seven choices $(7=$ extremely liberal, $6=$ liberal, $5=$ slightly liberal, $4=$ moderate, 3 =slightly conservative, $2=$ conservative and $1=$ extremely conservative).

We present estimates of equation 5 in Appendix Table A14. We include individual covariates, our set of exogenous controls and state fixed effects 
in all columns. In column 1, we present the estimate from an ordered probit regression where the dependent variable is whether respondents think they are liberal or conservative. We find a positive and statistically significant relationship between the gold rushes and the likelihood to report being liberal. The point estimate suggests that respondents in counties with gold discoveries during one of the gold rushes are 4 percent of a standard deviation more likely to report being liberal. In a further set of OLS specifications (not shown for space consideration), we find that respondents in counties with gold discoveries during one of the gold rushes are 2 percent more likely to report being either an extremely liberal, liberal or slightly liberal.

In columns $2-5$, we present estimates from probit regressions for the other four variables. We find a positive and statistically significant relationship between gold rush mining counties and the likelihood to be in favor of gun laws and legalizing marijuana. The estimates suggest that residents in gold rush counties are about three percent more likely to favor gun laws and five percent more likely to support legalizing marijuana. On the other hand, the estimates are not statistically significant for death penalty and abortion 32

To sum up, we find weak evidence that gold rush counties are more liberal in general. Individuals in gold rush counties report being slightly more liberal on average, but the estimated effect is quite small in comparison to the impact of the gold rushes on attitudes toward the LGBT population.

\section{Conclusion}

This paper provides empirical evidence that the current geographic distribution of the LGBT population is related to the largest mass migration in the history of the U.S.--gold rushes during the mid-to-late 19th centuryand to the lack of local religious institutions.

We first rely on census estimates of the LGBT population to analyze the association between the number of unmarried partnered households of the same sex and gold discovery in the West during the gold rushes. We find that gold mining counties with at least one discovery during a gold rush have significantly more LGBT individuals nowadays than other mining counties. We then provide evidence that residents of gold rush counties are currently more likely to report pro-LGBT attitudes.

\footnotetext{
${ }^{32}$ This finding for abortion is robust to the use of alternative questions on this topic.
} 
Our empirical findings have interesting policy implications. First, we provide evidence that a historical shock may have persistent effects on where people live, but also on attitudes. These findings suggest that economic policies or shocks such as migration of workers may shape social norms in the long-run. Second, our results point to a role for early religious institutions in shaping norms and attitudes (Cage and Rueda (2017); Nunn (2010)). That the initial institutional environment would affect norms and values is of particular importance for economic development (Bisin and Verdier (2011)). 


\section{References}

Abramitzky, R., Delavande, A. and Vasconcelos, L.: 2011, Marrying Up: the Role of Sex Ratio in Assortative Matching, American Economic Journal: Applied Economics 3(3), 124-57.

Acemoglu, D., Johnson, S. and Robinson, J. A.: 2001, The Colonial Origins of Comparative Development: An Empirical Investigation, American Economic Review 91(5), 1369-1401.

Ahlfeldt, G. M., Redding, S. J., Sturm, D. M. and Wolf, N.: 2015, The Economics of Density: Evidence from the Berlin Wall, Econometrica 83(6), 2127-2189.

Aksoy, C. G., Carpenter, C. S., Frank, J. and Huffman, M. L.: 2018, Gay Glass Ceilings: Sexual Orientation and Workplace Authority in the UK. IZA Discussion Paper 11574.

Alesina, A., Giuliano, P. and Nunn, N.: 2013, On the Origins of Gender Roles: Women and the Plough, Quarterly Journal of Economics 128(2), 469-530.

Algan, Y. and Cahuc, P.: 2010, Inherited Trust and Growth, American Economic Review 100(5), 2060-92.

Allegretto, S. A. and Arthur, M. M.: 2001, An Empirical Analysis of Homosexual/Heterosexual Male Earnings Differentials: Unmarried and Unequal?, ILR Review 54(3), 631-646.

Altemeyer, B.: 2002, Changes in Attitudes Toward Homosexuals, Journal of Homosexuality 42(2), 63-75.

Andersen, R. and Fetner, T.: 2008, Economic Inequality and Intolerance: Attitudes Toward Homosexuality in 35 Democracies, American Journal of Political Science 52(4), 942-958.

Anderson, S. and Ray, D.: 2010, Missing Women: Age and Disease, Review of Economic Studies 77(4), 1262-1300.

Angrist, J.: 2002, How do Sex Ratios Affect Marriage and Labor Markets? Evidence from America's Second Generation, Quarterly Journal of Economics 117(3), 997-1038. 
Antecol, H. and Steinberger, M. D.: 2013, Labor Supply Differences Between Married Heterosexual Women and Partnered Lesbians: A SemiParametric Decomposition Approach, Economic Inquiry 51(1), 783-805.

Asal, V., Sommer, U. and Harwood, P. G.: 2013, Original Sin: A CrossNational Study of the Legality of Homosexual Acts, Comparative Political Studies 46(3), 320-351.

Banerjee, A. and Iyer, L.: 2005, History, Institutions, and Economic Performance: The Legacy of Colonial Land Tenure Systems in India, American Economic Review 95(4), 1190-1213.

Baranov, V., De Haas, R. and Grosjean, P.: 2018, Men: Roots and Consequences of Masculinity Norms. Available at SSRN: https://ssrn.com/ abstract $=3185694$.

Barone, G. and Mocetti, S.: 2014, Natural Disasters, Growth and Institutions: A Tale of Two Earthquakes, Journal of Urban Economics 84, 5266.

Bazzi, S., Fiszbein, M. and Gebresilasse, M.: 2017, Frontier Culture: The Roots and Persistence of "Rugged Individualism" in the United States. NBER Working Paper 23997.

Bisin, A. and Verdier, T.: 2011, The Economics of Cultural Transmission and Socialization, in J. Benhabib, A. Bisin and M. Jackson (eds), Handbook of Social Economics, Vol. 1, Elsevier, pp. 339-416.

Black, D. A., Makar, H. R., Sanders, S. G. and Taylor, L. J.: 2003, The Earnings Effects of Sexual Orientation, ILR Review 56(3), 449-469.

Black, D. A., Sanders, S. G. and Taylor, L. J.: 2007, The Economics of Lesbian and Gay Families, Journal of Economic Perspectives 21(2), 5370 .

Black, D., Gates, G., Sanders, S. and Taylor, L.: 2000, Demographics of the Gay and Lesbian Population in the United States: Evidence from Available Systematic Data Sources, Demography 37(2), 139-154.

Black, D., Gates, G., Sanders, S. and Taylor, L.: 2002, Why do Gay Men Live in San Francisco?, Journal of Urban Economics 51(1), 54-76.

Blandford, J. M.: 2003, The Nexus of Sexual orientation and Gender in the Determination of Earnings, ILR Review 56(4), 622-642. 
Bleakley, H. and Lin, J.: 2012, Portage and Path Dependence, Quarterly Journal of Economics 127(2), 587-644.

Boyd, N. A.: 2003, Wide-Open Town: A History of Queer San Francisco to 1965, University of California Press.

Brodeur, A., Lekfuangfu, W. and Zylberberg, Y.: Forthcoming, War, Migration and the Origins of the Thai Sex Industry, Journal of the European Economic Association .

Buggle, J. C. and Durante, R.: 2017, Climate Risk, Cooperation, and the Co-Evolution of Culture and Institutions. CEPR Working Paper SP12380.

Buonanno, P., Durante, R., Prarolo, G. and Vanin, P.: 2015, Poor Institutions, Rich Mines: Resource Curse in the Origins of the Sicilian Mafia, Economic Journal 125(586), 175-202.

Cage, J. and Rueda, V.: 2017, Sex and the Mission: The Conflicting Effects of Early Christian Investments on Sub-Saharan Africa's HIV Epidemic. CEPR Working Paper DP12192.

Card, D., Mas, A. and Rothstein, J.: 2008, Tipping and the Dynamics of Segregation, Quarterly Journal of Economics 123(1), 177-218.

Carpenter, C. and Gates, G. J.: 2008, Gay and Lesbian Partnership: Evidence from California, Demography 45(3), 573-590.

Carranza, E.: 2014, Soil Endowments, Female Labor Force Participation, and the Demographic Deficit of Women in India, American Economic Journal: Applied Economics 6(4), 197-225.

Chang, S.: 2015, Criminalization of Homosexuality and Sex Ratios. IZA Discussion Paper 8801.

Christafore, D., Leguizamon, J. S. and Leguizamon, S.: 2013, Are Black Neighborhoods Less Welcoming to Homosexuals than White Neighborhoods?, Regional Science and Urban Economics 43(4), 579-589.

Clay, K. and Jones, R.: 2008, Migrating to Riches? Evidence from the California Gold Rush, Journal of Economic History 68(4), 997-1027.

Coffman, K. B., Coffman, L. C. and Ericson, K. M. M.: 2016, The Size of the LGBT Population and the Magnitude of Antigay Sentiment Are Substantially Underestimated, Management Science 63(10), 3168-3186. 
Conley, T. G.: 1999, GMM Estimation with Cross Sectional Dependence, Journal of Econometrics 92(1), 1-45.

Conley, T. G.: 2008, Spatial Econometrics, in S. N. Durlauf and L. E. Blume (eds), The New Palgrave Dictionary of Economics, Palgrave Macmillan.

Couttenier, M., Grosjean, P. and Sangnier, M.: 2017, The Wild West is Wild: The Homicide Resource Curse, Journal of the European Economic Association 15(3), 558-585.

Couttenier, M. and Sangnier, M.: 2015, Living in the Garden of Eden: Mineral Resources and Preferences for Redistribution, Journal of Comparative Economics 43(2), 243-256.

Davis, D. R. and Weinstein, D. E.: 2002, Bones, Bombs, and Break Points: The Geography of Economic Activity, American Economic Review 92(5), 1269-1289.

Dell, M., Lane, N. and Querubin, P.: Forthcoming, The Historical State, Local Collective Action, and Economic Development in Vietnam, Econometrica .

Dustmann, C., Fabbri, F. and Preston, I.: 2011, Racial Harassment, Ethnic Concentration, and Economic Conditions, Scandinavian Journal of Economics 113(3), 689-711.

Dustmann, C. and Preston, I.: 2001, Attitudes to Ethnic Minorities, Ethnic Context and Location Decisions, Economic Journal 111(470), 353-373.

Edin, P.-A., Fredriksson, P. and Aslund, O.: 2003, Ethnic Enclaves and the Economic Success of Immigrants-Evidence from a Natural Experiment, Quarterly Journal of Economics 118(1), 329-357.

Edlund, L. and Lee, C.: 2009, Son Preference, Sex Selection and Economic Development: Theory and Evidence from South Korea. Columbia University Discussion Paper 0809-16.

Fafchamps, M.: 2006, Development and Social Capital, Journal of Development Studies 42(7), 1180-1198.

Fernández, R. and Fogli, A.: 2009, Culture: An Empirical Investigation of Beliefs, Work, and Fertility, American Economic Journal: Macroeconomics 1(1), 146-77. 
Fisher, R., Gee, G. and Looney, A.: Forthcoming, Joint Filing by SameSex Couples after Windsor: Characteristics of Married Tax Filers in 2013 and 2014, Demography .

Gates, G. J.: 2013, Geography of the LGBT Population, in A. Baumle (ed.), International Handbook on the Demography of Sexuality, Springer, pp. 229-242.

Gates, G. J.: 2015, Comparing LGBT Rankings by Metro Area: 1990-2014. Williams Institute, UCLA School of Law.

Giuliano, P. and Nunn, N.: 2017, Understanding Cultural Persistence and Change. NBER Working Paper 23617.

Goodrich, C. A.: 1859, The Land we Live in: Travels, Sketches and Adventures in North and South America, H. M. Rulison Queen City Publishing House.

Grosjean, P.: 2014, A History of Violence: The Culture of Honor and Homicide in the US South, Journal of the European Economic Association 12(5), 1285-1316.

Grosjean, P. and Khattar, R.: Forthcoming, It's Raining Men! Hallelujah?: The Long-Run Consequences of Male-Biased Sex Ratios, Review of Economic Studies .

Guiso, L., Sapienza, P. and Zingales, L.: 2006, Does Culture Affect Economic Outcomes?, Journal of Economic Perspectives 20(2), 23-48.

Hegarty, P. K. and Pratto, F.: 2001, Sexual Orientation Beliefs: Their Relationship to Anti-Gay Attitudes and Biological Determinist Arguments, Journal of Homosexuality 41(1), 121-35.

Hesketh, T. and Xing, Z. W.: 2006, Abnormal Sex Ratios in Human Populations: Causes and Consequences, Proceedings of the National Academy of Sciences 103(36), 13271-13275.

Holliday, J. S.: 2015, The World Rushed in: The California Gold Rush Experience, University of Oklahoma Press.

Hsiang, S. M.: 2010, Temperatures and Cyclones Strongly Associated with Economic Production in the Caribbean and Central America, Proceedings of the National Academy of Sciences 107(35), 15367-15372. 
Hurtado, A. L.: 1999, Sex, Gender, Culture, and a Great Event: The California Gold Rush, Pacific Historical Review 68(1), 1-19.

Knack, S. and Keefer, P.: 1997, Does Social Capital Have an Economic Payoff? A Cross-Country Investigation, Quarterly Journal of Economics 112(4), 1251-1288.

Lipsky, W.: 2006, Gay and Lesbian San Francisco, Arcadia Publishing.

Maffly-Kipp, L. F.: 1994, Religion and Society in Frontier California, Yale University Press.

Maurer, S. E. and Potlogea, A.: 2017, Male-Biased Demand Shocks and Women's Labor Force Participation: Evidence from Large Oil Field Discoveries. Working Paper 2017-08 University of Konstanz.

Miguel, E. and Roland, G.: 2011, The Long-Run Impact of Bombing Vietnam, Journal of Development Economics 96(1), 1-15.

Munshi, K.: 2003, Networks in the Modern Economy: Mexican Migrants in the US Labor Market, Quarterly Journal of Economics 118(2), 549-599.

Nugent, W.: 2007, Into the West: The Story of Its People, Vintage.

Nunn, N.: 2010, Religious Conversion in Colonial Africa, American Economic Review: Papers \& Proceedings 100(2), 147-52.

Nunn, N. and Wantchekon, L.: 2011, The Slave Trade and the Origins of Mistrust in Africa, American Economic Review 101(7), 3221-52.

Redding, S. J., Sturm, D. M. and Wolf, N.: 2011, History and Industry Location: Evidence from German Airports, Review of Economics and Statistics 93(3), 814-831.

Schacht, R. and Kramer, K. L.: 2016, Patterns of Family Formation in Response to Sex Ratio Variation, PloS one 11(8), e0160320.

Smart, M. J. and Whittemore, A. H.: 2017, There Goes the Gaybourhood? Dispersion and Clustering in a Gay and Lesbian Real Estate Market in Dallas TX, 1986-2012, Urban Studies 54(3), 600-615.

Stephan, G. E. and McMullin, D. R.: 1982, Tolerance of Sexual Nonconformity: City Size as a Situational and Early Learning Determinant, American Sociological Review pp. 411-415. 
Tabellini, G.: 2008a, Institutions and Culture, Journal of the European Economic Association 6(2-3), 255-294.

Tabellini, G.: 2008b, The Scope of Cooperation: Values and Incentives, Quarterly Journal of Economics 123(3), 905-950.

Teso, E.: Forthcoming, The Long-Term Effect of Demographic Shocks on the Evolution of Gender Roles: Evidence from the Transatlantic Slave Trade, Journal of the European Economic Association .

Voigtländer, N. and Voth, H.-J.: 2012, Persecution Perpetuated: the Medieval Origins of Anti-Semitic Violence in Nazi Germany, Quarterly Journal of Economics 127(3), 1339-1392.

Weichselbaumer, D.: 2003, Sexual Orientation Discrimination in Hiring, Labour Economics 10(6), 629-642.

William, B. (ed.): 1999, A Year of Mud and Gold: San Francisco in Letters and Diaries, 1849-1850, University of Nebraska Press.

Worthen, M. G. F.: 2012, Understanding College Student Attitudes toward LGBT Individuals, Sociological Focus 45(4), 285-305.

Yue, A.: 2013, Lesbian, Gay, Bisexual, Transgender (LGBT) Migration, in I. Ness (ed.), The Encyclopedia of Global Human Migration, Wiley Blackwell. 
Figure 1: Gold Discoveries During the Gold Rushes

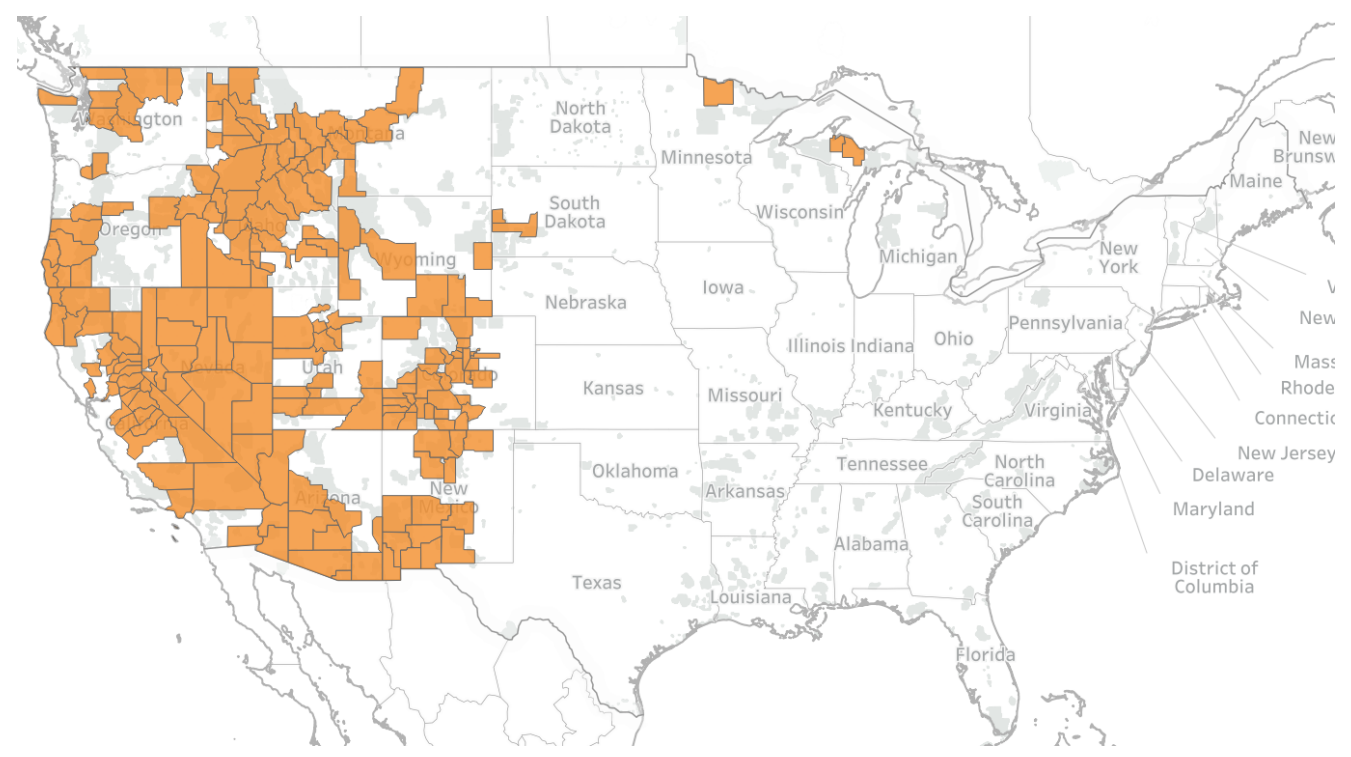

Notes: Based on data from the Mineral Resources Data System. Orange indicates that a county had at least one gold discovery during the gold rushes (1848-1899).

Figure 2: Gold Mining Counties Without Gold Rush Discoveries

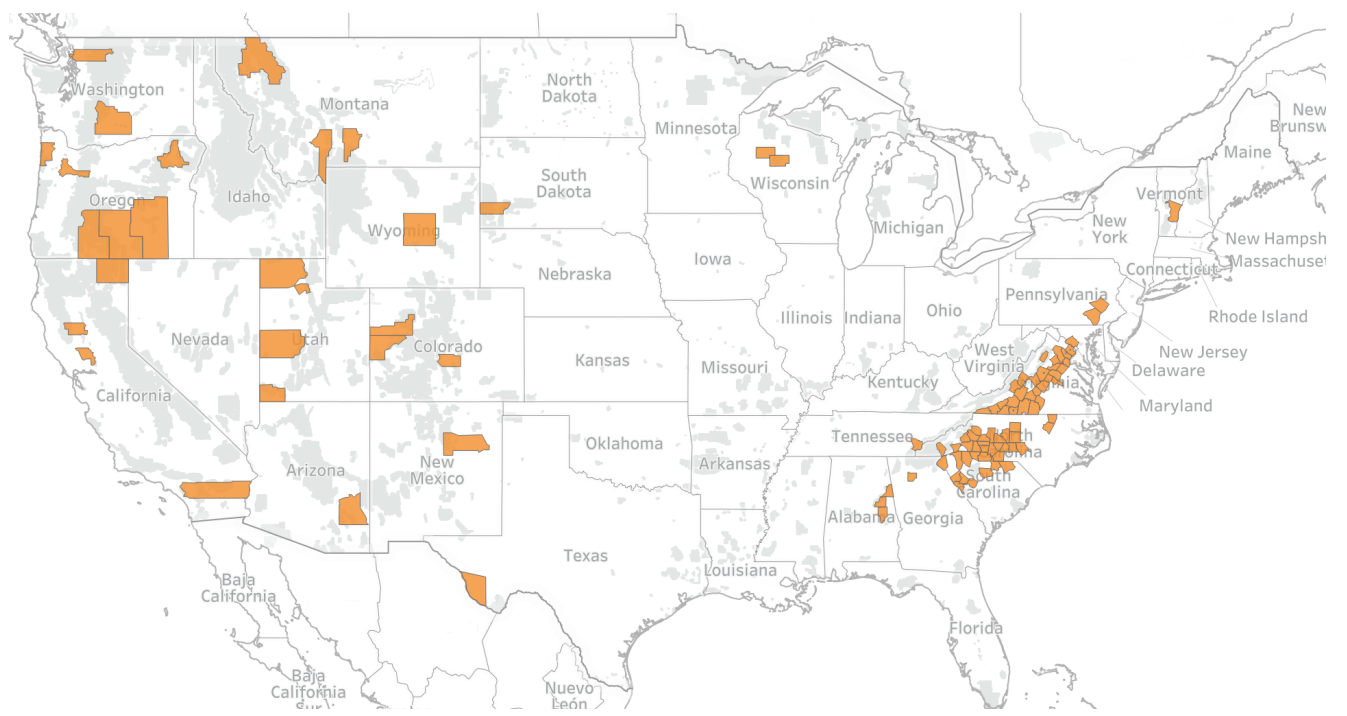

Notes: Based on data from the Mineral Resources Data System. Orange indicates that a county had at least one gold discovery before or after the gold rushes (1848-1899) and no gold discoveries during one of the gold rushes. Orange also indicates counties with gold discoveries in the East during the gold rushes. 
Figure 3: Unmarried Partner Households of the Same Sex

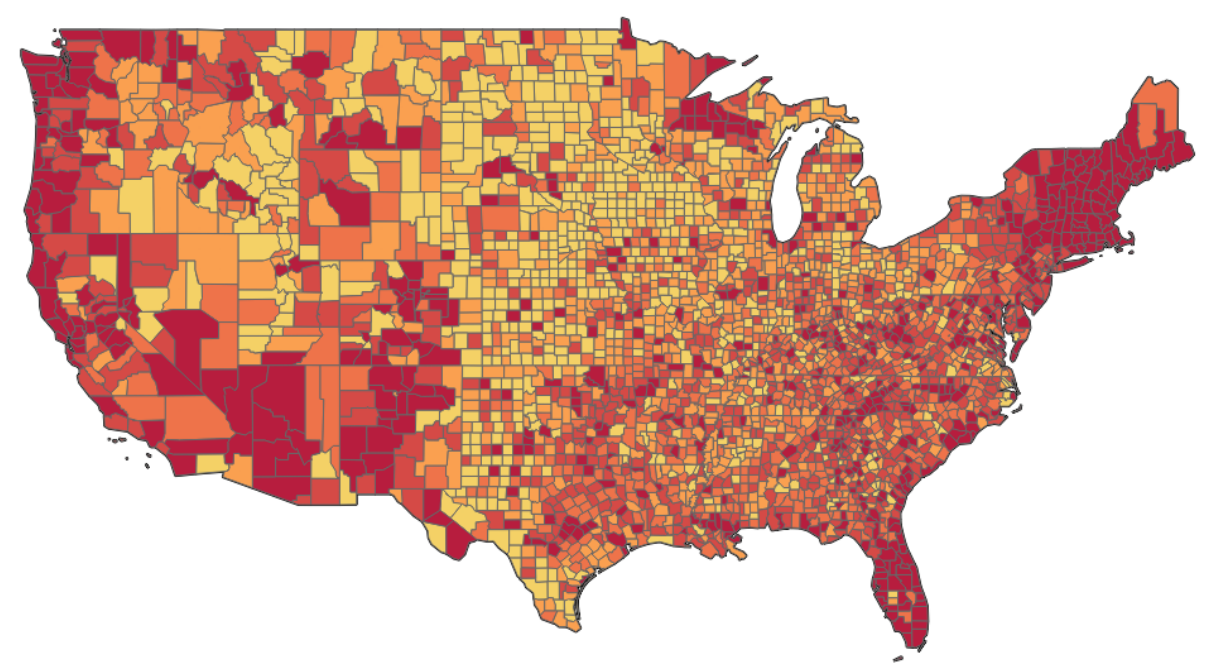

Notes: Unmarried Partner Households of the Same Sex per Capita in 2010. Light yellow indicates the lower quintile and dark red the top quintile.

Figure 4: Gold Mining Counties and Notable Place of Worship

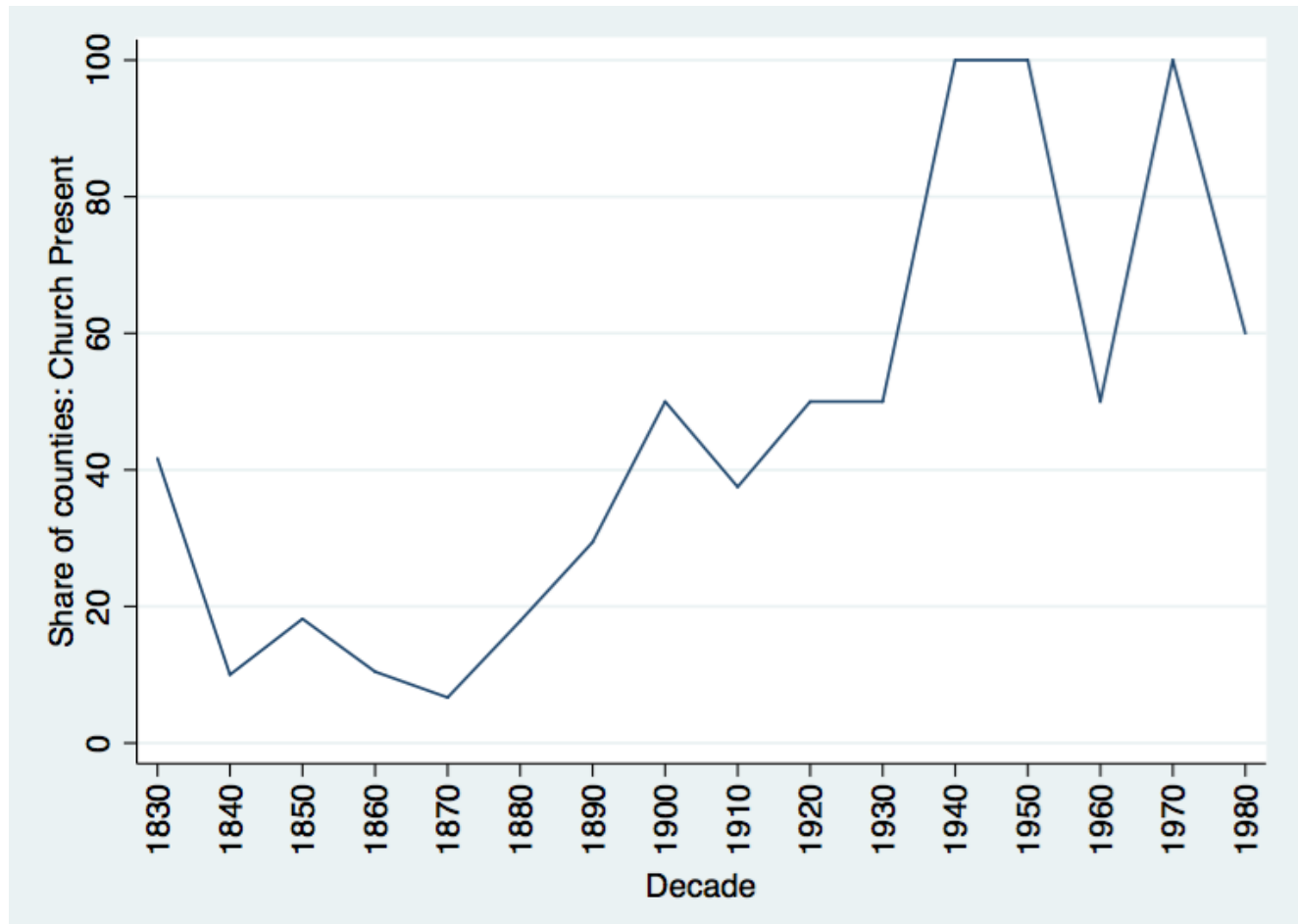

Notes: Share of gold mining counties with at least one notable place of worship at the time of gold discovery by decade. Based on data from National Register of Historic Places. 


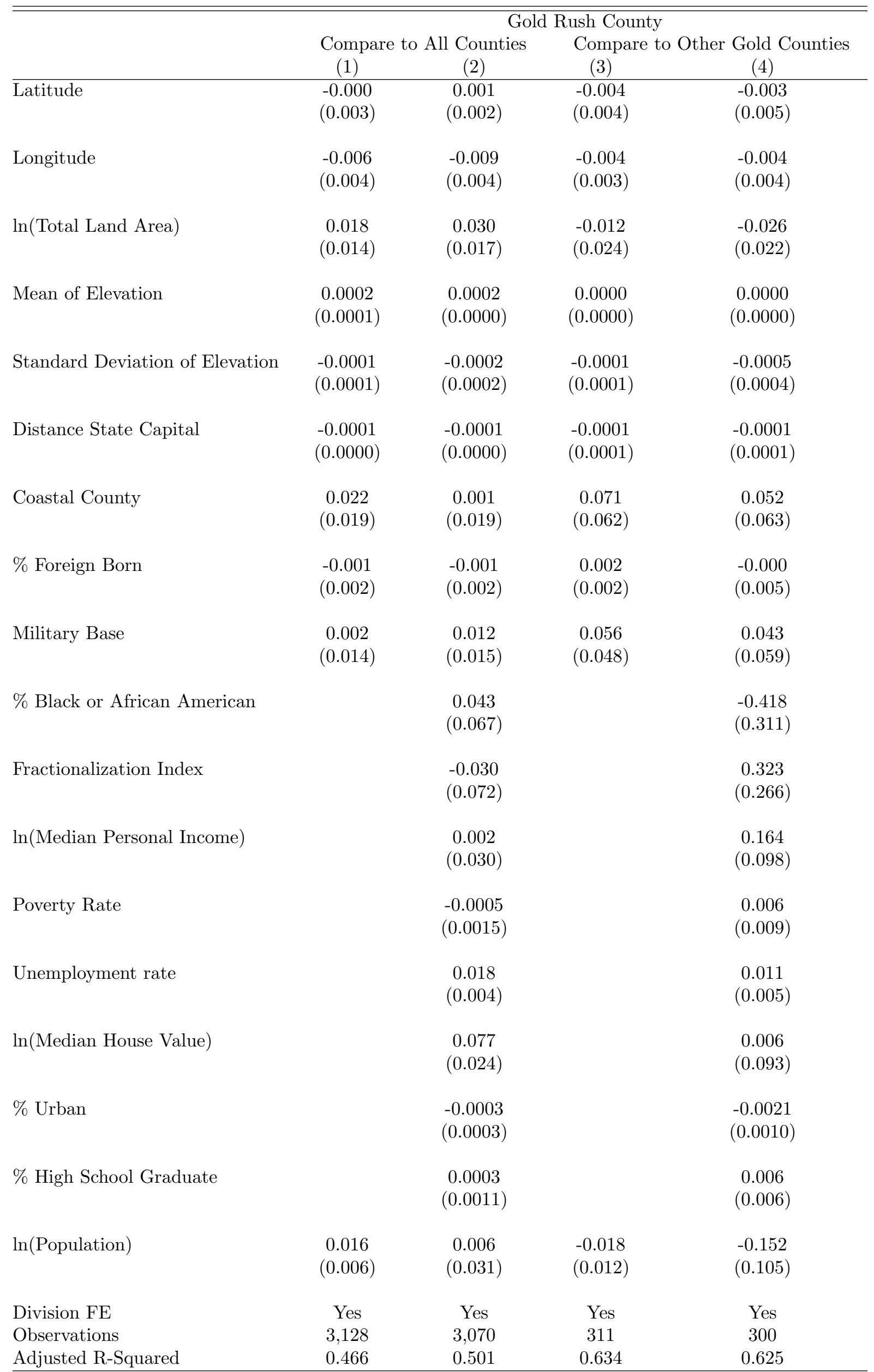

Notes: The unit of observation is a county. The dependent variable is a dummy for whether the county had at least one gold discovery during the gold rushes. Standard errors clustered by state are reported between parentheses. Columns 1-2 include all U.S. 42 unties. Columns 3-4 restrict the sample to counties with at least one gold discovery. 
Table 2: Gold Rushes and Male-to-Female Ratio: Unbalanced Panel

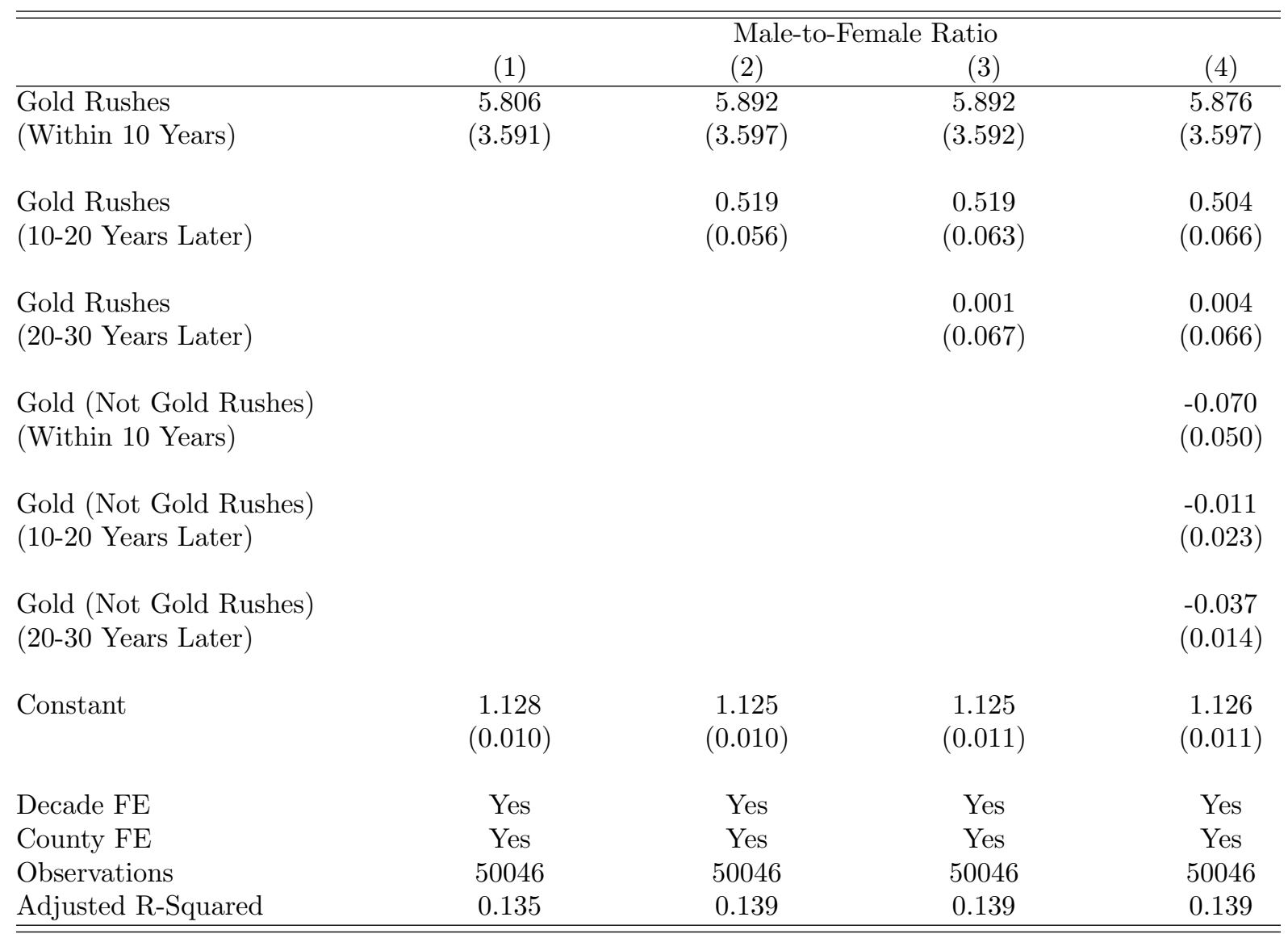

Notes: The unit of observation is a county-decade. The dependent variable is the male-to-female ratio. The time period is 1820-2000. Gold Rushes (Within 10 Years) equals one for county-decade observations with the earliest gold rush discovery and zero otherwise. Gold Rushes (10-20 Years Later) and Gold Rushes (20-30 Years Later) equal one for county-decade observations with respectively the earliest gold rush discovery 10-20 years earlier and 20-30 years earlier. Gold-Not Gold Rushes- (Within 10 Years) equals one for county-decade observations with the earliest gold discovery before or after the gold rushes and zero otherwise. Gold Rushes-Not Gold Rushes-(10-20 Years Later) and Gold Rushes-Not Gold Rushes- (20-30 Years Later) equal one for county-decade observations with respectively the earliest nongold rush discovery 10-20 years earlier and 20-30 years earlier. Standard errors clustered by state are reported between parentheses. Columns 1-4 include county and decade fixed effects. 
Table 3: Gold Rushes and Notable Places of Worship

\begin{tabular}{lccccc}
\hline \hline Probit & \multicolumn{5}{c}{ Place of Worship at the Moment of Gold Discovery } \\
& $(1)$ & $(2)$ & $(3)$ & $(4)$ & $(5)$ \\
\hline Gold Rushes & -0.348 & -0.338 & -0.379 & -0.378 & -0.328 \\
& $(0.064)$ & $(0.077)$ & $(0.081)$ & $(0.094)$ & $(0.113)$ \\
& & & & & \\
$\ln$ (population) & Yes & Yes & Yes & Yes & Yes \\
Region FE & No & No & Yes & No & No \\
Division FE & No & No & No & Yes & No \\
State FE & No & No & No & No & Yes \\
Exogenous controls & No & Yes & Yes & Yes & Yes \\
Observations & 311 & 311 & 308 & 299 & 279 \\
Pseudo R-Squared & 0.228 & 0.261 & 0.263 & 0.267 & 0.310 \\
\hline
\end{tabular}

Notes: The unit of observation is a county. The sample is restricted to counties with at least one gold discovery at any time. The dependent variable is a dummy which equals one if a notable place of worship existed at the time of gold discovery and zero otherwise. Gold Rushes equals one for counties with at least one gold discovery during the gold rushes and zero otherwise. Marginal effects are reported. Standard errors clustered by state are reported between parentheses. Columns 1-5 include the (log of) 2010 county population. The set of exogenous controls include latitude, longitude, total land area, mean and standard deviation of elevation, distance to the state's capital and a dummy for coastal counties.

Table 4: Simple Difference: Main Estimates

\begin{tabular}{|c|c|c|c|c|c|c|}
\hline & \multicolumn{6}{|c|}{ Ln(1 + Unmarried Partner Households Same Sex $)$} \\
\hline & $(1)$ & $(2)$ & $(3)$ & (4) & $(5)$ & $(6)$ \\
\hline Gold Rushes & 0.143 & 0.133 & 0.175 & 0.117 & 0.116 & 0.123 \\
\hline$\beta$ & $(0.056)$ & $(0.058)$ & $(0.045)$ & $(0.046)$ & $(0.048)$ & $(0.049)$ \\
\hline Gold (Not Gold Rushes) & & 0.015 & 0.003 & -0.023 & -0.052 & -0.042 \\
\hline$\lambda$ & & $(0.024)$ & $(0.021)$ & $(0.020)$ & $(0.017)$ & $(0.016)$ \\
\hline $\ln ($ population $)$ & Yes & Yes & Yes & Yes & Yes & Yes \\
\hline Region FE & No & No & No & Yes & No & No \\
\hline Division FE & $\mathrm{No}$ & No & No & No & Yes & No \\
\hline State FE & No & No & No & No & No & Yes \\
\hline Exogenous controls & No & No & Yes & Yes & Yes & Yes \\
\hline$P(\beta \neq \lambda)$ & & 0.088 & 0.001 & 0.008 & 0.002 & 0.001 \\
\hline Observations & 3,128 & 3,128 & 3,128 & 3,128 & 3,128 & 3,128 \\
\hline Adjusted R-Squared & 0.956 & 0.956 & 0.958 & 0.961 & 0.963 & 0.965 \\
\hline
\end{tabular}

Notes: The unit of observation is a county. The dependent variable is the natural log of one plus the number of unmarried partner households of the same sex in 2010. Gold Rushes equals one for counties with at least one gold discovery during the gold rushes and zero otherwise. Gold (Not Gold Rushes) equals one for counties with at least one gold discovery before or after the gold rushes and zero otherwise. Standard errors clustered by state are reported between parentheses. Columns 1-6 include the (log of) 2010 county population. The set of exogenous controls include latitude, longitude, total land area, mean and standard deviation of elevation, distance to the state's capital and a dummy for coastal counties. 


\begin{tabular}{|c|c|c|c|c|c|c|}
\hline & \multicolumn{6}{|c|}{ Ln(1 + Unmarried Partner Households Same Sex $)$} \\
\hline & $(1)$ & $(2)$ & (3) & $(4)$ & $(5)$ & $(6)$ \\
\hline Gold & $\begin{array}{c}0.104 \\
(0.045)\end{array}$ & $\begin{array}{c}0.026 \\
(0.026)\end{array}$ & $\begin{array}{c}0.006 \\
(0.025)\end{array}$ & $\begin{array}{l}-0.029 \\
(0.019)\end{array}$ & $\begin{array}{l}-0.063 \\
(0.017)\end{array}$ & $\begin{array}{l}-0.038 \\
(0.012)\end{array}$ \\
\hline Gold $\times$ Gold Rushes & & $\begin{array}{c}0.144 \\
(0.056)\end{array}$ & $\begin{array}{c}0.177 \\
(0.048)\end{array}$ & $\begin{array}{c}0.101 \\
(0.048)\end{array}$ & $\begin{array}{c}0.080 \\
(0.050)\end{array}$ & $\begin{array}{c}0.097 \\
(0.054)\end{array}$ \\
\hline $\ln ($ population $)$ & Yes & Yes & Yes & Yes & Yes & Yes \\
\hline Region FE & No & No & No & Yes & No & No \\
\hline Division FE & No & No & No & No & Yes & No \\
\hline State FE & No & No & No & No & No & Yes \\
\hline Exogenous controls & No & No & Yes & Yes & Yes & Yes \\
\hline Observations & 3,128 & 3,128 & 3,128 & 3,128 & 3,128 & 3,128 \\
\hline Adjusted R-Squared & 0.955 & 0.956 & 0.958 & 0.961 & 0.963 & 0.965 \\
\hline
\end{tabular}

Notes: The unit of observation is a county. The dependent variable is the natural log of one plus the number of unmarried partner households of the same sex in 2010. Gold equals one for counties with at least one gold discovery and zero otherwise. Gold Rushes equals one for counties with at least one gold discovery during the gold rushes and zero otherwise. Standard errors clustered by state are reported between parentheses. Columns 1-6 include the (log of) 2010 county population. The set of exogenous controls include latitude, longitude, total land area, mean and standard deviation of elevation, distance to the state's capital and a dummy for coastal counties.

Table 6: Differences-in-Differences: Robustness Checks

\begin{tabular}{|c|c|c|c|c|c|}
\hline & & $(1+U n ı$ & Partner & aolds Sa & \\
\hline & (1) & $(2)$ & $(3)$ & $(4)$ & $(5)$ \\
\hline Gold & -0.041 & -0.038 & -0.038 & -0.041 & -0.022 \\
\hline & $(0.014)$ & $(0.013)$ & $(0.013)$ & $(0.014)$ & $(0.043)$ \\
\hline Gold $\times$ Gold Rushes & 0.094 & 0.097 & 0.097 & 0.094 & 0.101 \\
\hline & $(0.054)$ & $(0.054)$ & $(0.055)$ & $(0.054)$ & $(0.054)$ \\
\hline Other Minerals & 0.008 & & & 0.008 & \\
\hline & $(0.018)$ & & & $(0.018)$ & \\
\hline $\ln$ (population) & Yes & Yes & Yes & Yes & Yes \\
\hline State FE & Yes & Yes & Yes & Yes & Yes \\
\hline Exogenous controls & Yes & Yes & Yes & Yes & Yes \\
\hline$\%$ of Foreign Born & No & Yes & No & Yes & No \\
\hline Military Base & No & No & Yes & Yes & No \\
\hline Observations & 3,128 & 3,128 & 3,128 & 3,128 & 434 \\
\hline Adjusted R-Squared & 0.965 & 0.965 & 0.965 & 0.965 & 0.965 \\
\hline
\end{tabular}

Notes: The unit of observation is a county. The dependent variable is the natural log of one plus the number of unmarried partner households of the same sex in 2010. Gold equals one for counties with at least one gold discovery and zero otherwise. Gold Rushes equals one for counties with at least one gold discovery during the gold rushes and zero otherwise. Standard errors clustered by state are reported between parentheses. Columns 1-6 include the (log of) 2010 county population and our set of exogenous controls (see Table 5). In column 1, we add a control for other minerals (oil or gas resources, copper, iron, nickel or silver). Column 2 includes a control for the share of foreign born. Column 3 includes a dummy for whether the county is housing a U.S. military base. Column 5 restricts the sample to the Western region. 
Table 7: Simple Difference: Neighbor

\begin{tabular}{|c|c|c|c|c|c|c|}
\hline \multirow{3}{*}{ Gold Rushes } & \multicolumn{6}{|c|}{ Ln(1 + Unmarried Partner Households Same Sex $)$} \\
\hline & $(1)$ & $(2)$ & $(3)$ & $(4)$ & $(5)$ & $(6)$ \\
\hline & $\begin{array}{c}0.101 \\
(0.047)\end{array}$ & $\begin{array}{c}0.069 \\
(0.091)\end{array}$ & $\begin{array}{c}0.132 \\
(0.082)\end{array}$ & $\begin{array}{l}-0.037 \\
(0.071)\end{array}$ & $\begin{array}{l}-0.049 \\
(0.054)\end{array}$ & $\begin{array}{c}0.020 \\
(0.045)\end{array}$ \\
\hline Neighbor & $\begin{array}{c}0.046 \\
(0.044)\end{array}$ & $\begin{array}{c}0.045 \\
(0.045)\end{array}$ & $\begin{array}{c}0.182 \\
(0.063)\end{array}$ & $\begin{array}{c}0.023 \\
(0.064)\end{array}$ & $\begin{array}{c}0.002 \\
(0.062)\end{array}$ & $\begin{array}{c}0.053 \\
(0.062)\end{array}$ \\
\hline $\begin{array}{l}\text { Gold Rushes } \times \\
\text { Neighbor }\end{array}$ & & $\begin{array}{c}0.148 \\
(0.059)\end{array}$ & $\begin{array}{c}0.295 \\
(0.073)\end{array}$ & $\begin{array}{c}0.127 \\
(0.080)\end{array}$ & $\begin{array}{c}0.096 \\
(0.082)\end{array}$ & $\begin{array}{c}0.150 \\
(0.088)\end{array}$ \\
\hline $\ln ($ population $)$ & Yes & Yes & Yes & Yes & Yes & Yes \\
\hline Region FE & No & No & No & Yes & No & No \\
\hline Division FE & No & No & No & No & Yes & No \\
\hline State FE & No & No & No & No & No & Yes \\
\hline Exogenous controls & No & No & Yes & Yes & Yes & Yes \\
\hline Observations & 3,128 & 3,128 & 3,128 & 3,128 & 3,128 & 3,128 \\
\hline Adjusted R-Squared & 0.955 & 0.955 & 0.959 & 0.961 & 0.962 & 0.964 \\
\hline
\end{tabular}

Notes: The unit of observation is a county. The dependent variable is the natural log of one plus the number of unmarried partner households of the same sex in 2010. Gold Rushes equals one for counties with at least one gold discovery during the gold rushes and zero otherwise. Neighbor equals one for counties neighboring a Gold Rushes county and zero otherwise. Standard errors clustered by state are reported between parentheses. Columns 1-6 include the (log of) 2010 county population. The set of exogenous controls include latitude, longitude, total land area, mean and standard deviation of elevation, distance to the state's capital and a dummy for coastal counties. 
Table 8: Differences-in-Differences: Socioeconomic Characteristics

\begin{tabular}{lcccccc}
\hline \hline & \multicolumn{6}{c}{ Ln(1+ Unmarried Partner Households Same Sex $)$} \\
& $(1)$ & $(2)$ & $(3)$ & $(4)$ & $(5)$ & $(6)$ \\
\hline Gold & -0.053 & -0.050 & -0.041 & -0.065 & -0.045 & -0.052 \\
& $(0.014)$ & $(0.015)$ & $(0.014)$ & $(0.017)$ & $(0.016)$ & $(0.020)$ \\
\multirow{3}{*}{ Gold $\times$ Gold Rushes } & & & & & & \\
& 0.092 & 0.094 & 0.095 & 0.075 & 0.088 & 0.062 \\
& $(0.055)$ & $(0.054)$ & $(0.048)$ & $(0.042)$ & $(0.050)$ & $(0.039)$
\end{tabular}

Additional Controls

Demographic Mechanism:

$\%$ Black or African American

Yes

Yes

Fractionalization Index

Yes

Yes

Economic Mechanism:

Median Personal Income

Poverty Rate

Unemployment rate

Urban Mechanism:

Median House Value

$\%$ House Less $\$ 100 \mathrm{~K}$

$\%$ House More $\$ 500 \mathrm{~K}$

\% Urban

Population Density

Education Mechanism:

\% High School Graduate

$\ln$ (population)

State FE

Exogenous controls

Other Minerals

$\%$ of Foreign Born

Military Base

Observations

\begin{tabular}{|c|c|c|c|c|c|}
\hline & Yes & & & & Yes \\
\hline & Yes & & & & Yes \\
\hline & & Yes & & & Yes \\
\hline & & Yes & & & Yes \\
\hline & & Yes & & & Yes \\
\hline & & & Yes & & Yes \\
\hline & & & Yes & & Yes \\
\hline & & & Yes & & Yes \\
\hline & & & Yes & & Yes \\
\hline & & & Yes & & Yes \\
\hline & & & & Yes & Yes \\
\hline Yes & Yes & Yes & Yes & Yes & Yes \\
\hline Yes & Yes & Yes & Yes & Yes & Yes \\
\hline Yes & Yes & Yes & Yes & Yes & Yes \\
\hline Yes & Yes & Yes & Yes & Yes & Yes \\
\hline Yes & Yes & Yes & Yes & Yes & Yes \\
\hline Yes & Yes & Yes & Yes & Yes & Yes \\
\hline 3,070 & 3,070 & 3,070 & 3,070 & 3,070 & 3,070 \\
\hline 0.966 & 0.966 & 0.966 & 0.968 & 0.966 & 0.969 \\
\hline
\end{tabular}

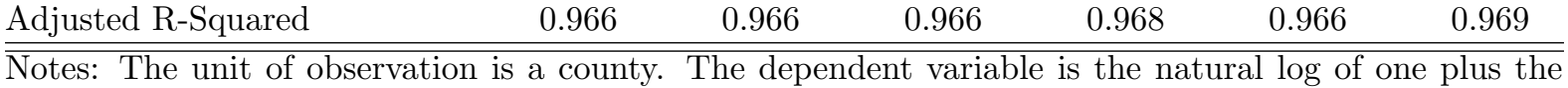
number of unmarried partner households of the same sex in 2010. Gold equals one for counties with at least one gold discovery and zero otherwise. Gold Rushes equals one for counties with at least one gold discovery during the gold rushes and zero otherwise. Standard errors clustered by state are reported between parentheses. Columns 1-6 include the (log of) 2010 county population. The set of exogenous controls include latitude, longitude, total land area, mean and standard deviation of elevation, distance to the state's capital and a dummy for coastal counties. We also control for other minerals (oil or gas resources, copper, iron, nickel or silver), the share of foreign born and for whether the county is housing a U.S. military base. 


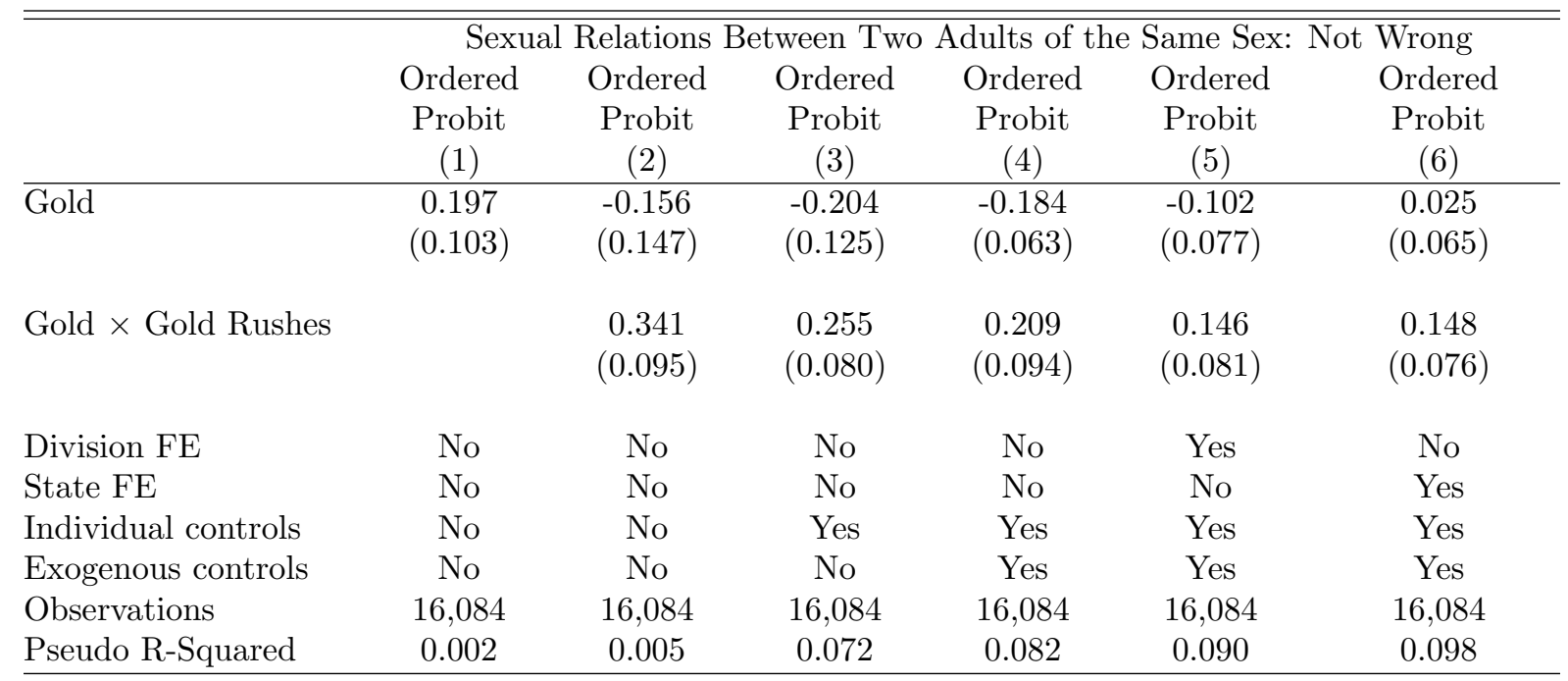

Notes: The unit of observation is a respondent. The period covered is 1993-2014. Attitudes toward LGBT is assessed through the following question: "What about sexual relations between two adults of the same sex-do you think it is" where respondents have four choices $(4=$ not wrong at all, $3=$ wrong only sometimes, $2=$ almost always wrong and $1=$ always wrong). Gold equals one for counties with at least one gold discovery and zero otherwise. Gold Rushes equals one for counties with at least one gold discovery during the gold rushes and zero otherwise. Standard errors clustered by state are reported between parentheses. The set of exogenous controls include latitude, longitude, total land area, mean and standard deviation of elevation, distance to the state's capital and a dummy for coastal counties. The set of individual controls include the following variables: gender, age, age squared, six education dummies, three race dummies and five marital status dummies.

Table 10: Fundamentalist or Liberal?: GSS

\begin{tabular}{|c|c|c|c|c|c|c|}
\hline & $\begin{array}{c}\text { Ordered } \\
\text { Probit } \\
(1)\end{array}$ & $\begin{array}{c}\text { Currentl } \\
\text { Ordered } \\
\text { Probit } \\
(2)\end{array}$ & $\begin{array}{c}\text { ondament } \\
\text { Ordered } \\
\text { Probit } \\
(3)\end{array}$ & $\begin{array}{c}\text { Moderat } \\
\text { Ordered } \\
\text { Probit } \\
(4)\end{array}$ & $\begin{array}{c}\text { Liberal? } \\
\text { Ordered } \\
\text { Probit } \\
(5)\end{array}$ & $\begin{array}{c}\text { Ordered } \\
\text { Probit } \\
(6)\end{array}$ \\
\hline Gold & $\begin{array}{c}0.160 \\
(0.082)\end{array}$ & $\begin{array}{l}-0.150 \\
(0.117)\end{array}$ & $\begin{array}{c}-0.168 \\
(0.099)\end{array}$ & $\begin{array}{c}-0.156 \\
(0.056)\end{array}$ & $\begin{array}{l}-0.110 \\
(0.072)\end{array}$ & $\begin{array}{c}0.014 \\
(0.070)\end{array}$ \\
\hline Gold $\times$ Gold Rushes & & $\begin{array}{c}0.288 \\
(0.065)\end{array}$ & $\begin{array}{c}0.196 \\
(0.050)\end{array}$ & $\begin{array}{c}0.191 \\
(0.048)\end{array}$ & $\begin{array}{c}0.126 \\
(0.043)\end{array}$ & $\begin{array}{c}0.120 \\
(0.046)\end{array}$ \\
\hline Division FE & No & No & No & No & Yes & No \\
\hline State FE & No & No & No & No & No & Yes \\
\hline Individual controls & No & No & Yes & Yes & Yes & Yes \\
\hline Exogenous controls & No & No & No & Yes & Yes & Yes \\
\hline Observations & 28,436 & 28,436 & 28,436 & 28,436 & 28,436 & 28,436 \\
\hline Pseudo R-Squared & 0.001 & 0.004 & 0.046 & 0.055 & 0.060 & 0.067 \\
\hline
\end{tabular}

Notes: The unit of observation is a respondent. The period covered is 1993-2014. Fundamentalism is assessed through the following question: "How fundamentalist is $\mathrm{r}$ currently" where respondents have three choices $(1=$ Fundamentalist, $2=$ Moderate, and $3=$ Liberal). Gold equals one for counties with at least one gold discovery and zero otherwise. Gold Rushes equals one for counties with at least one gold discovery during the gold rushes and zero otherwise. Standard errors clustered by state are reported between parentheses. The set of exogenous controls include latitude, longitude, total land area, mean and standard deviation of elevation, distance to the state's capital and a dummy for coastal counties. The set of individual controls include the following variables: gender, age, age squared, six education dummies, three race dummies and five marital status dummies. 


\section{Appendix: NOT FOR PUBLICATION}

Figure A1: Imaginary Men Ball During the 1849 California Gold Rush

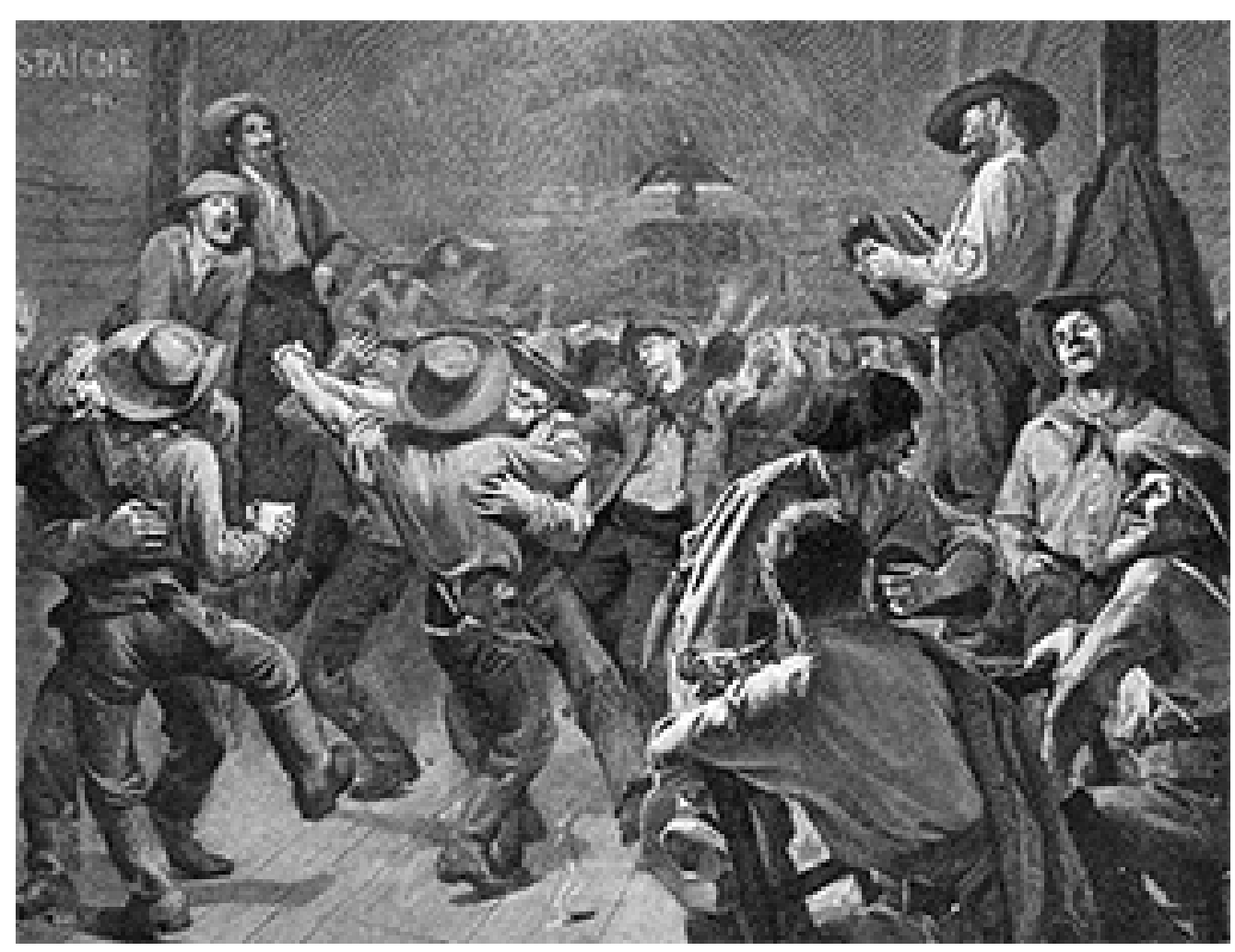

Source: 1891 etching by Andre Castaigne. 
Figure A2: Men Dancing in the Old West

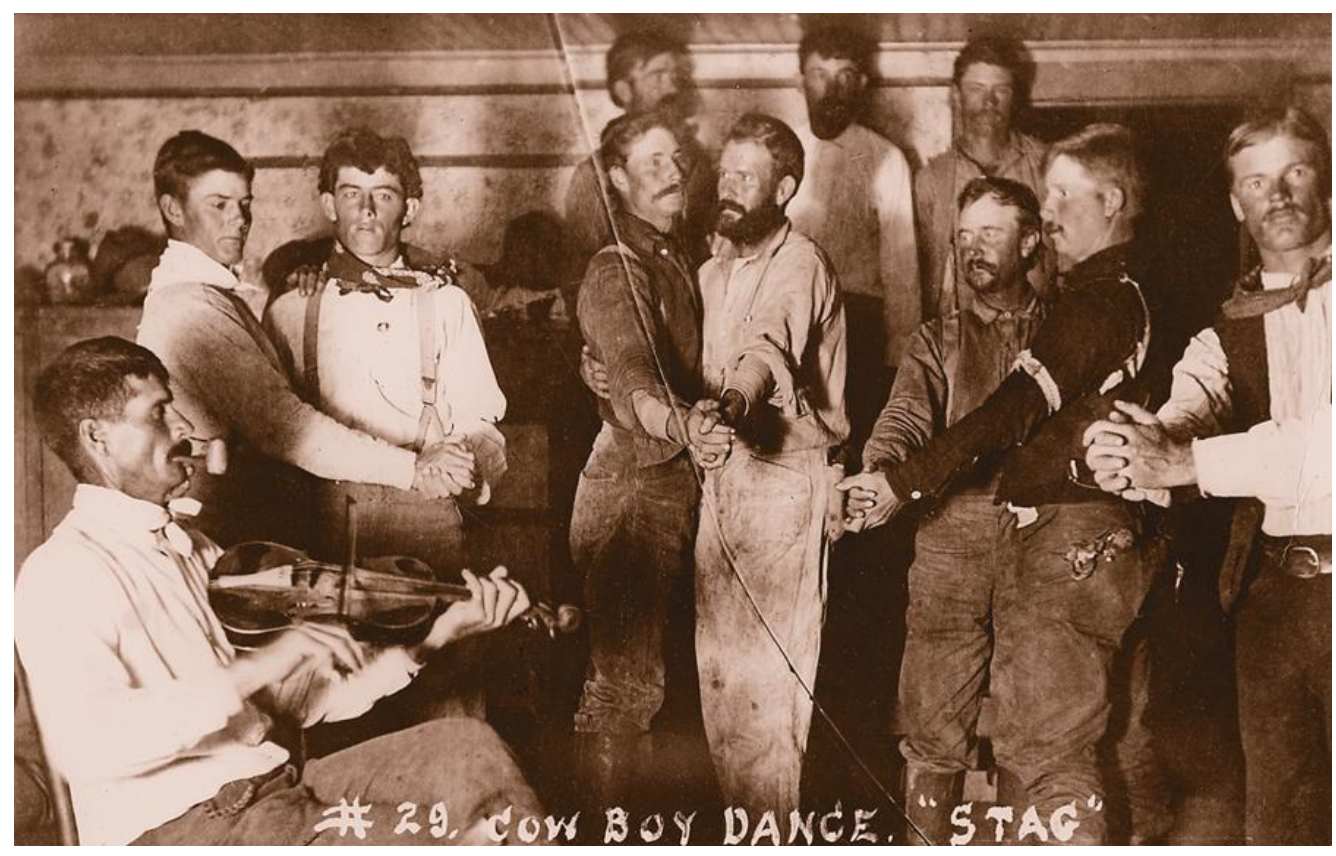

Source: True West Archive.

Figure A3: Married Couples who Have Filed Jointly

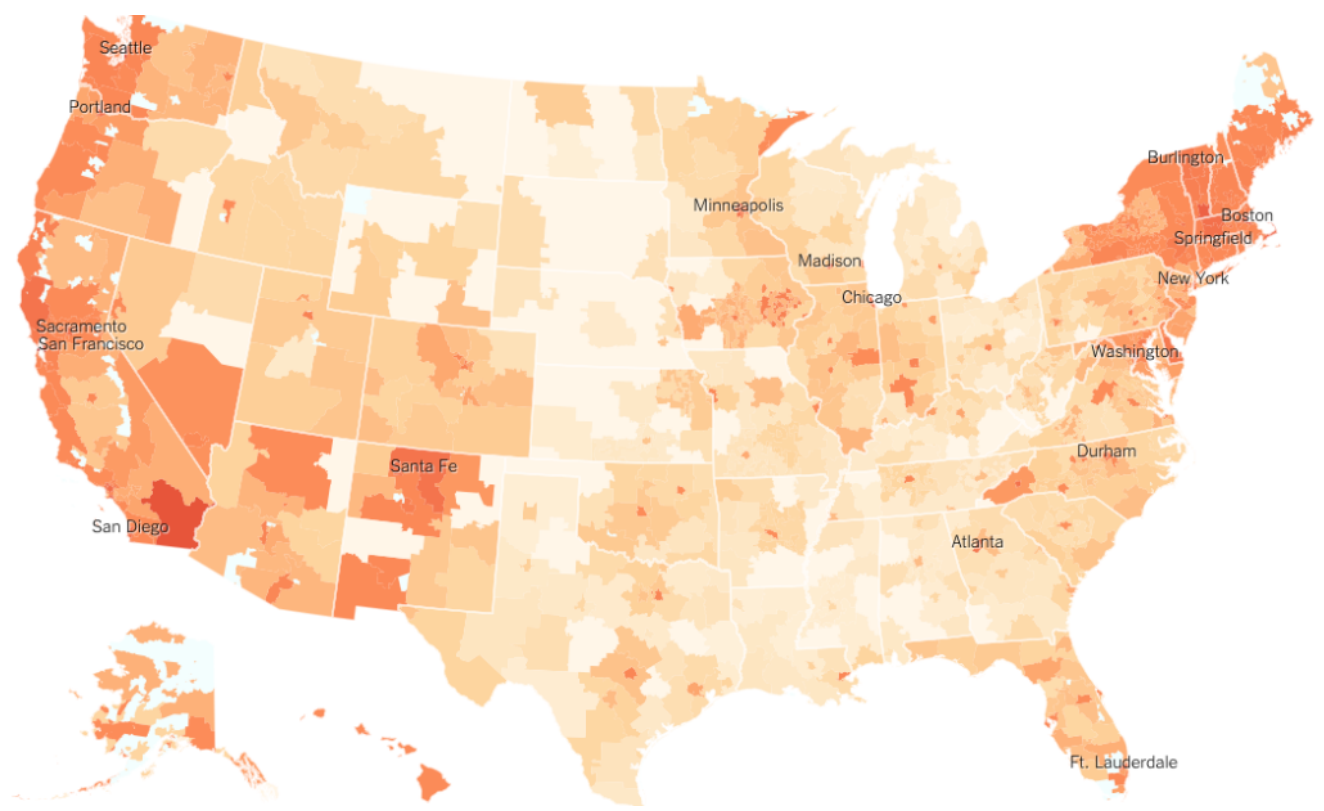

Notes: Same-sex marriage as a percentage of all marriages for married couples who have filed jointly on their tax return. Data presented at the three-digit zip code area. No data in areas where there are fewer than 500 married couples. 
Figure A4: Gold Rush Discoveries in Alaska: 1848-1899

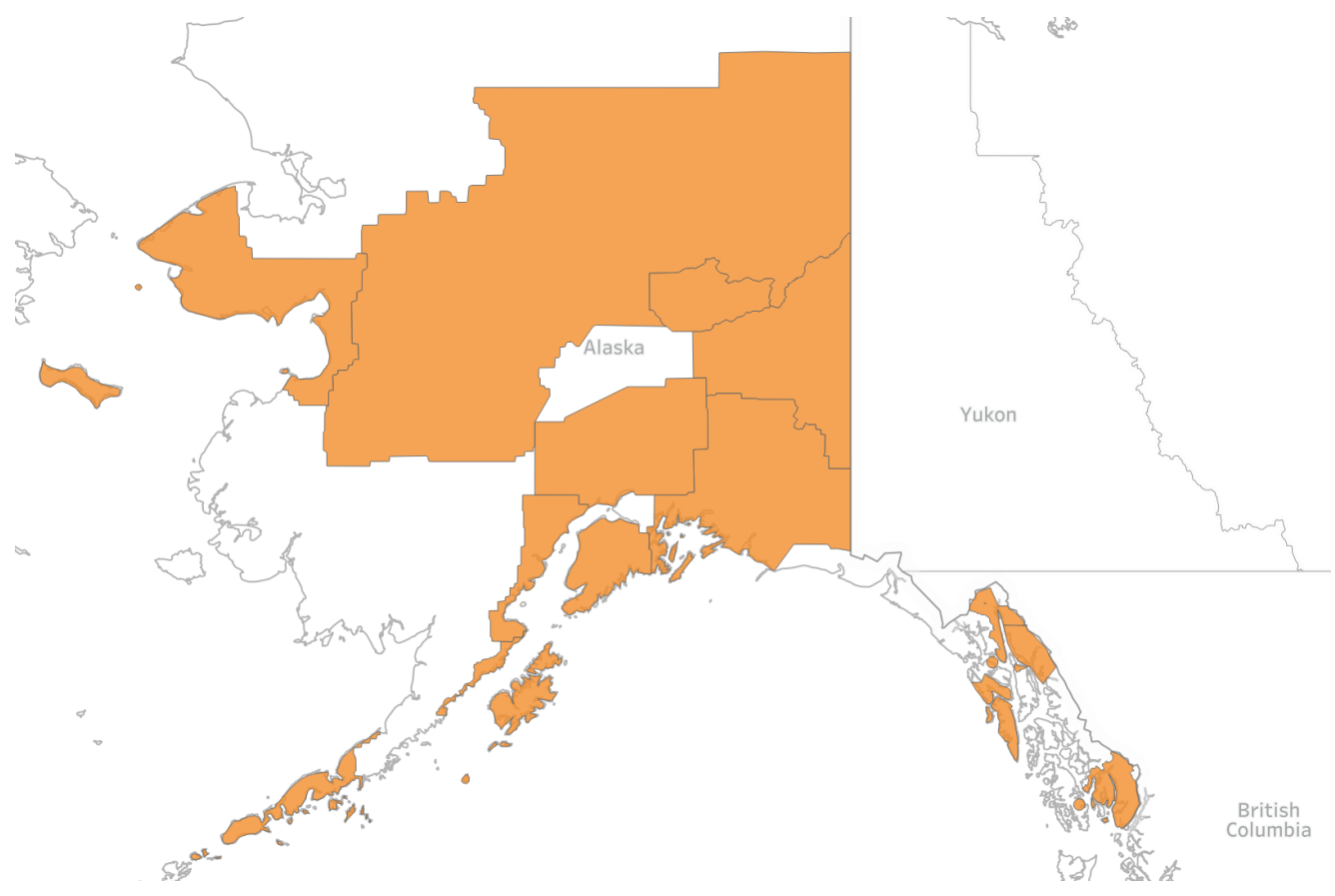

Notes: Based on data from the Mineral Resources Data System. Orange indicates gold discoveries during the gold rushes, only 1848-1899.

Figure A5: Gold Rush Discoveries: 1848-1859

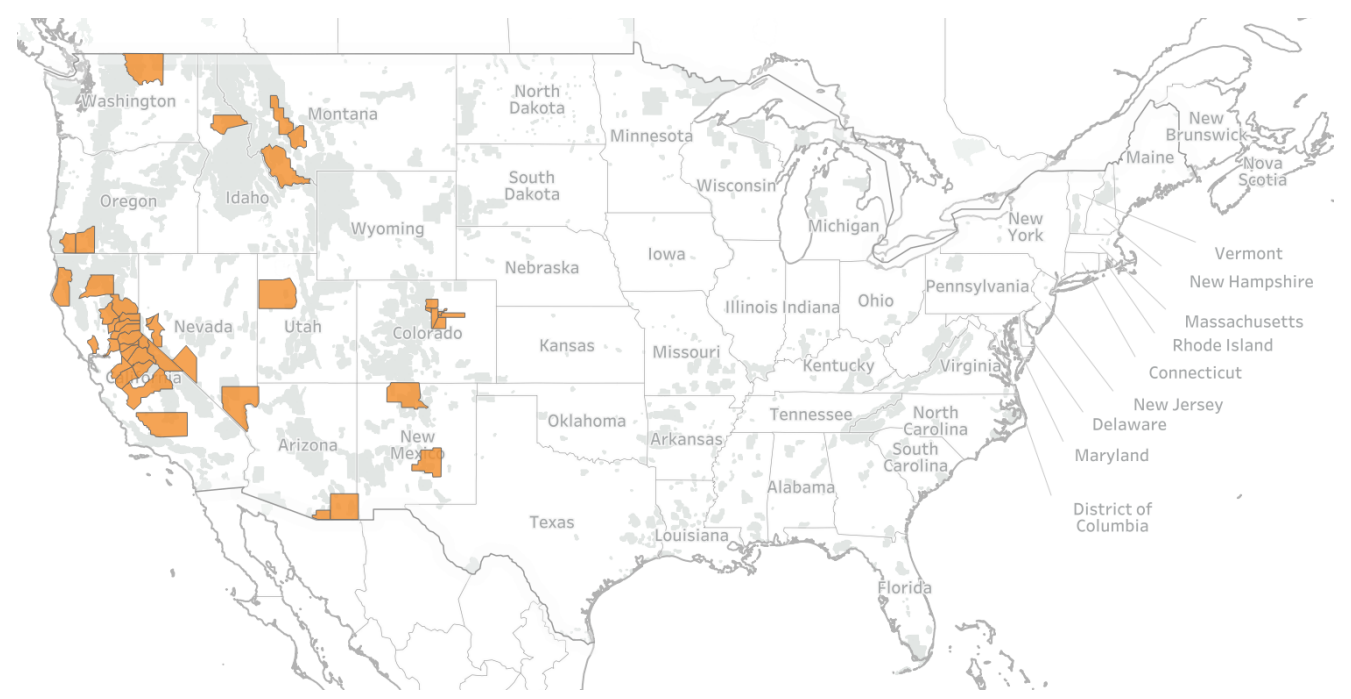

Notes: Based on data from the Mineral Resources Data System. Orange indicates gold discoveries during the gold rushes, only 1848-1859. 
Figure A6: Gold Rush Discoveries: 1860-1869

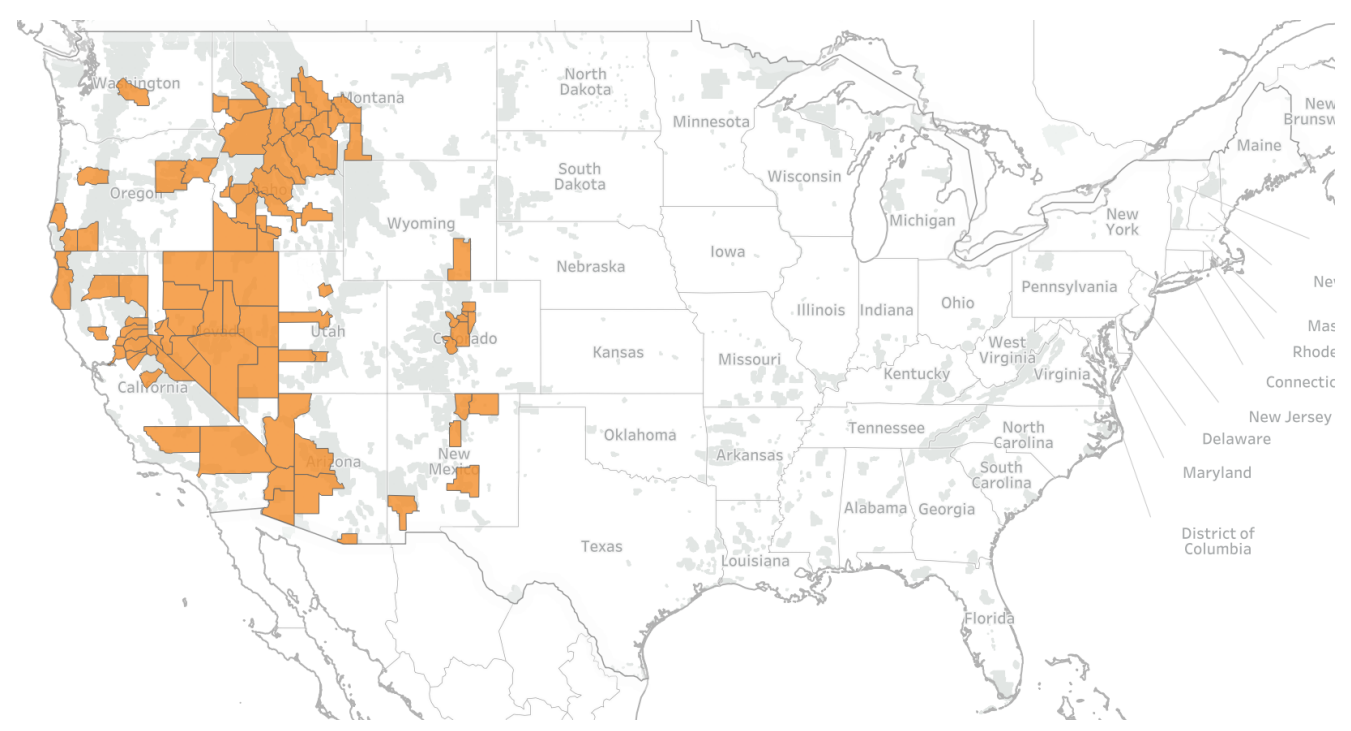

Notes: Based on data from the Mineral Resources Data System. Orange indicates gold discoveries during the gold rushes, only 1860-1869.

Figure A7: Gold Rush Discoveries: 1870-1899

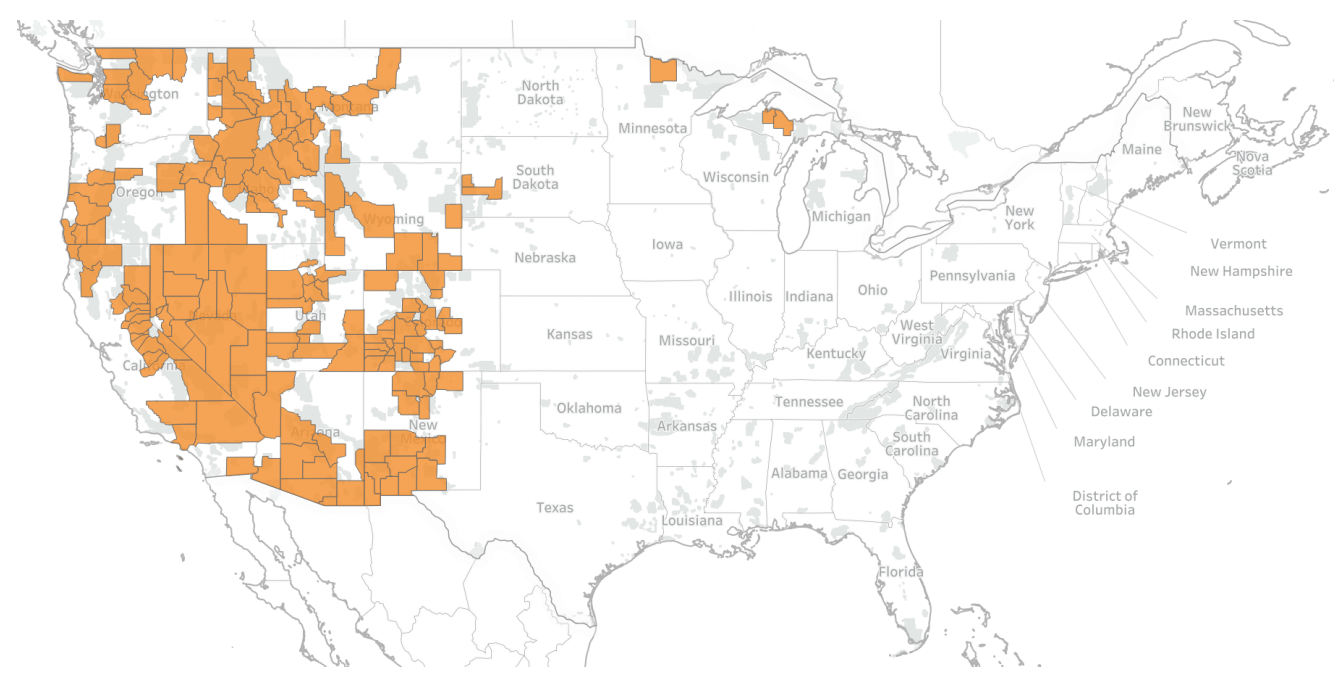

Notes: Based on data from the Mineral Resources Data System. Orange indicates gold discoveries during the gold rushes, only 1870-1899. 
Figure A8: Male-to-Female Ratio in 1860

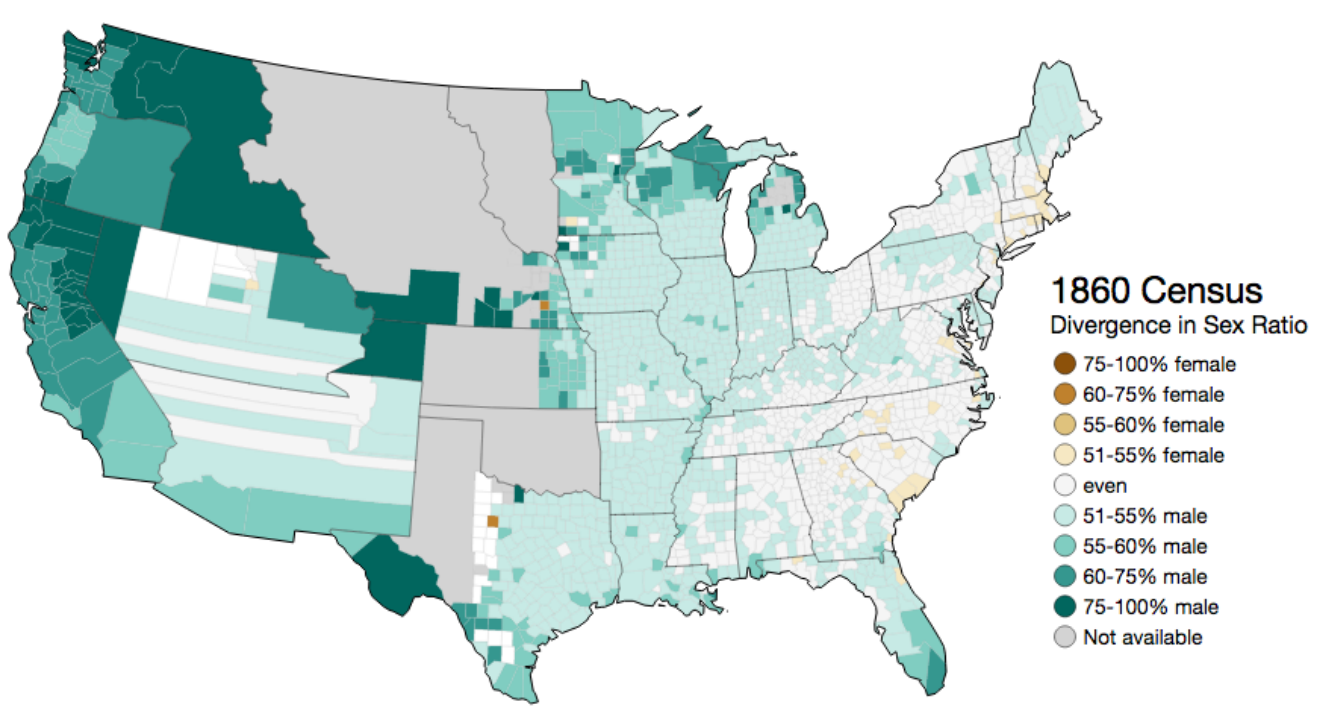

Notes: Figure from ?. Data from the NHGIS. Male-to-female ratio in 1860.

Figure A9: Male-to-Female Ratio in 1870

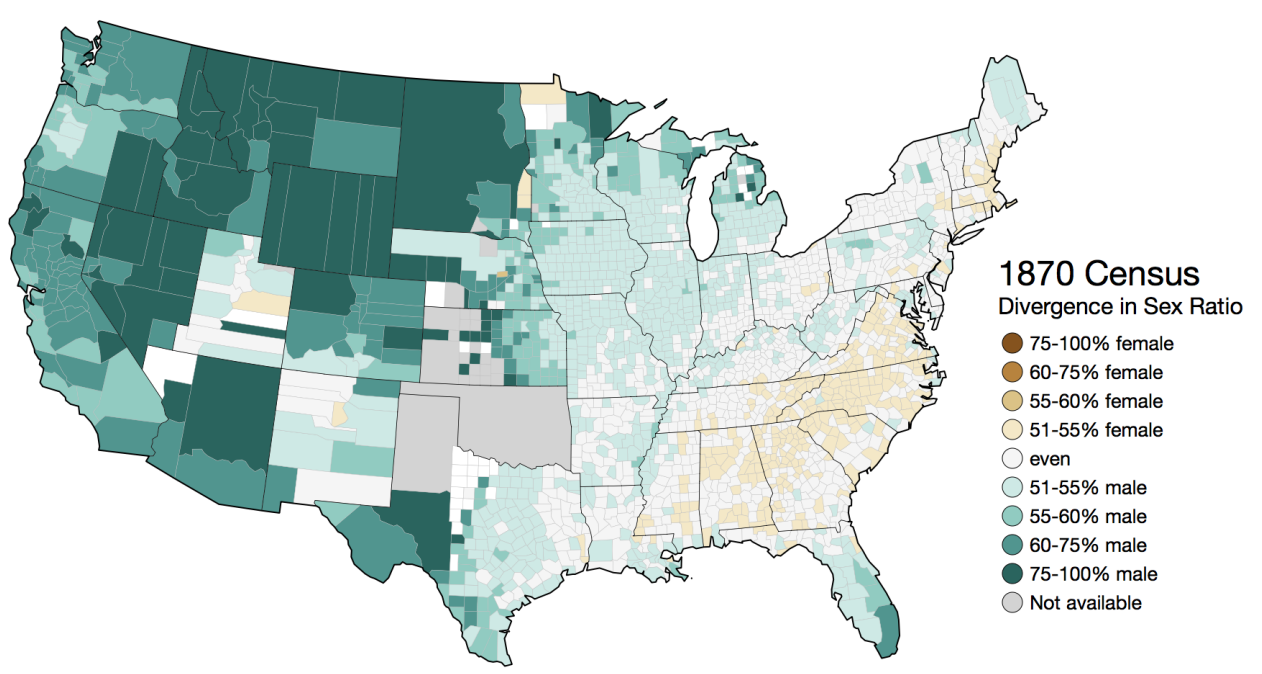

Notes: Figure from ?. Data from the NHGIS. Male-to-female ratio in 1870. 
Figure A10: Male-to-Female Ratio in 1960

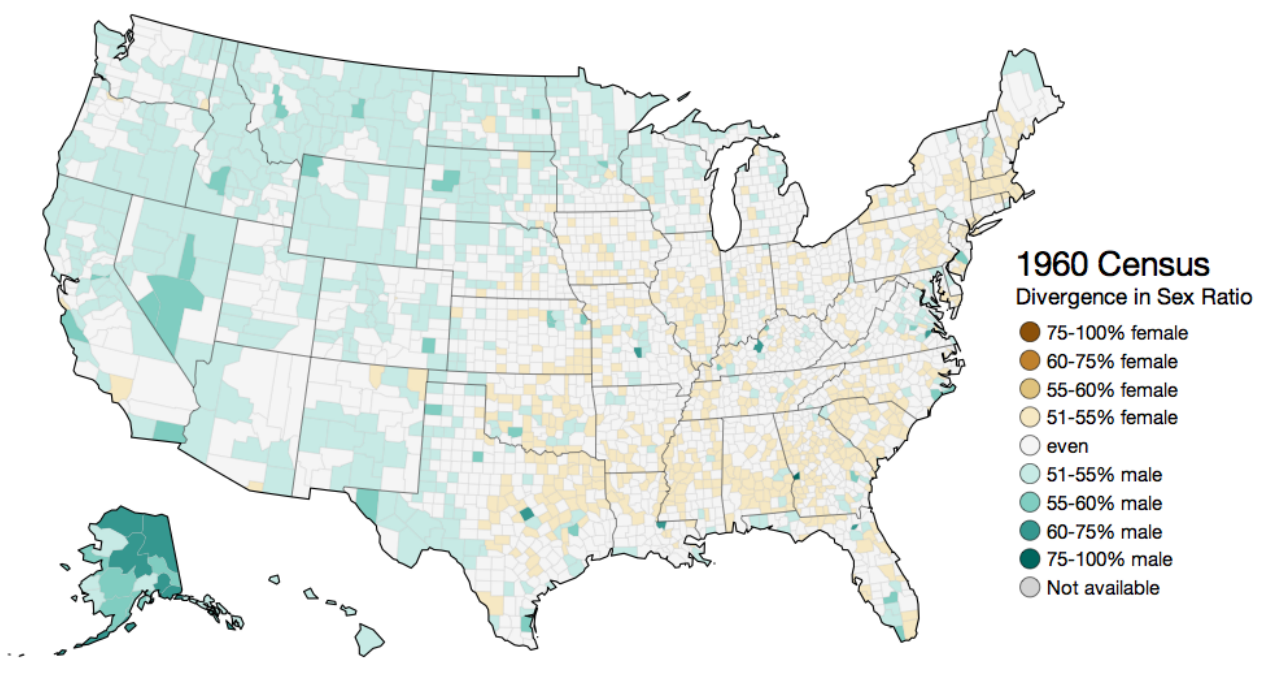

Notes: Figure from ?. Data from the NHGIS. Male-to-female ratio in 1960.

Figure A11: Male-to-Female Ratio

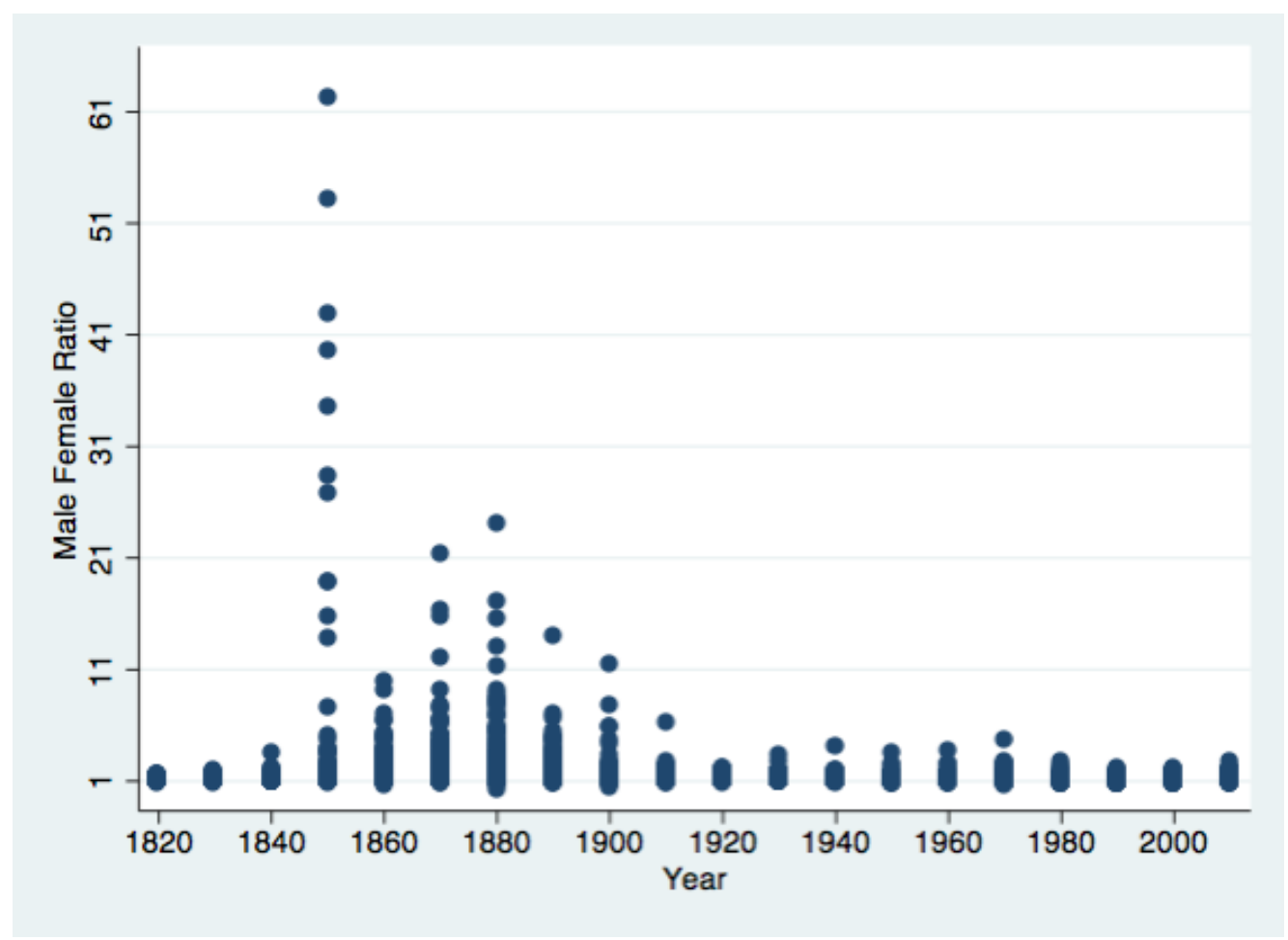

Notes: Male-to-Female Ratio across all counties. 
Figure A12: Gold Discoveries During the Gold Rushes: Intensity

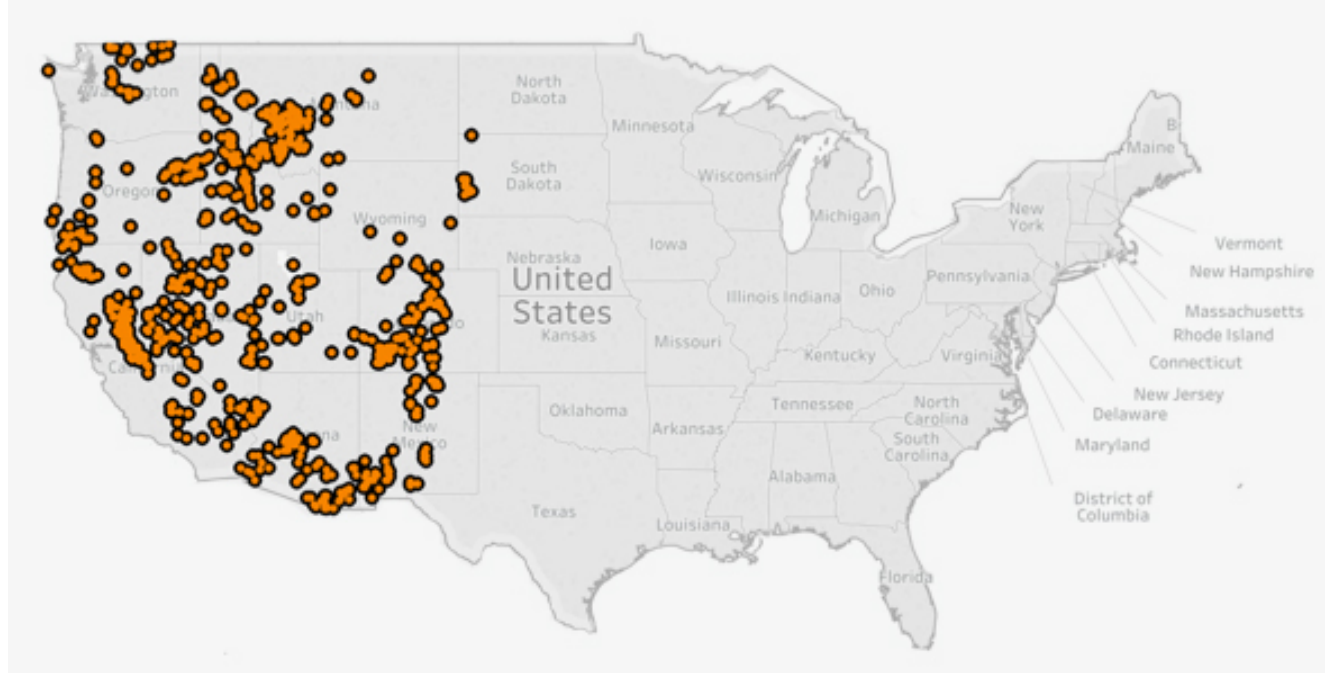

Notes: Based on data from the Mineral Resources Data System. Dots indicate gold discoveries during the gold rushes (1848-1899).

Figure A13: Sexual Relations Between Same Sex Adults Not Wrong at All

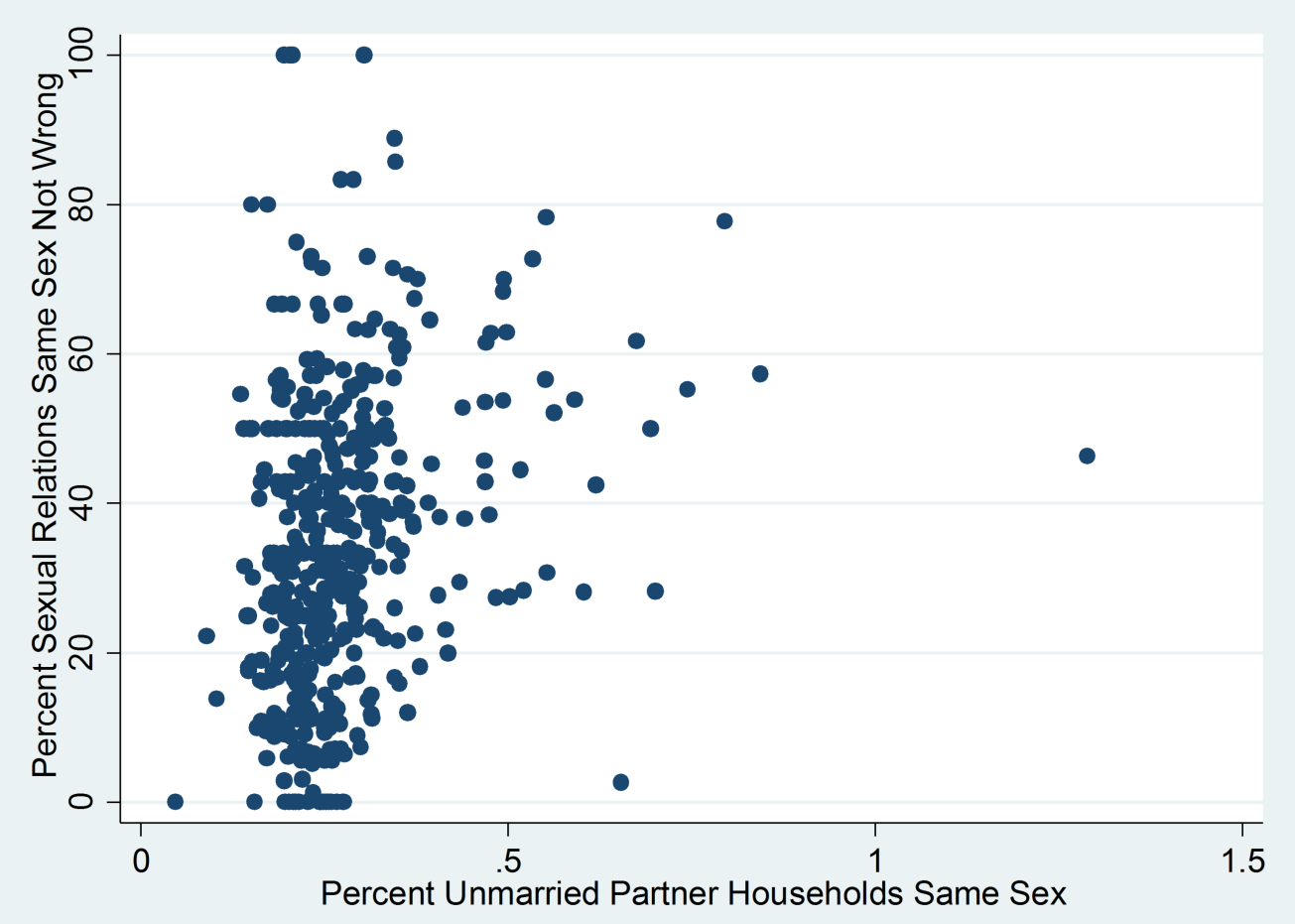

Figure A14: Based on data from the General Social Survey. Relationship between unmarried partner households same sex per capita and the percentage of respondents reporting "Not wrong at all" to the following question: "What about sexual relations between two adults of the same sex-do you think it is always wrong, almost always wrong, wrong only sometimes, or not wrong at all?" The unit of observation is a county. 
Table A1: Gold Rushes and Male-to-Female Ratio: Unbalanced Panel

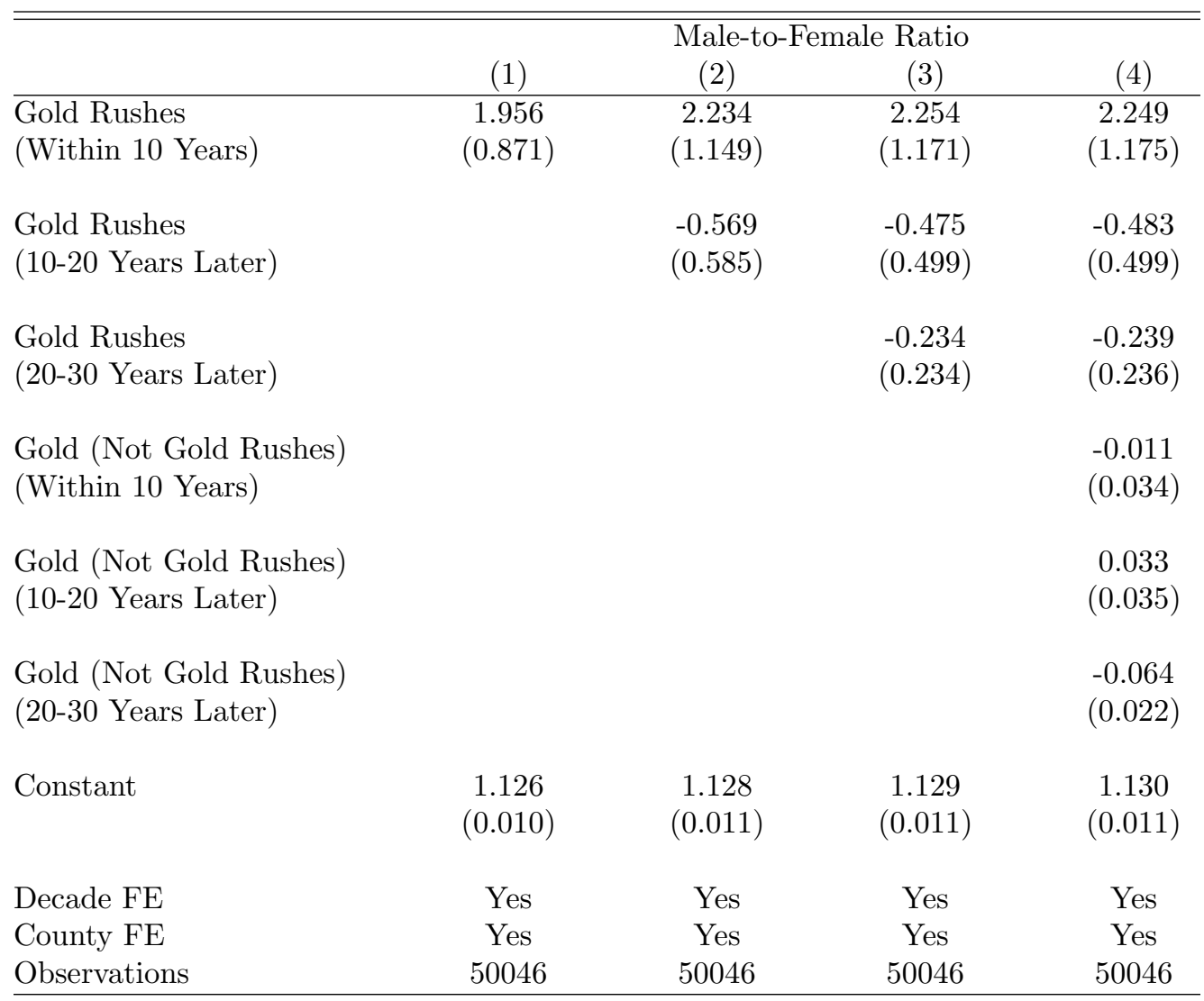

Notes: The unit of observation is a county-decade. The dependent variable is the maleto-female ratio. The time period is 1820-2000. Gold Rushes (Within 10 Years) equals one for county-decade observations with at least one gold rush discovery and zero otherwise. Gold Rushes (10-20 Years Later) and Gold Rushes (20-30 Years Later) equal one for county-decade observations with respectively at least one gold rush discovery 10-20 years earlier and 20-30 years earlier. Gold-Not Gold Rushes- (Within 10 Years) equals one for county-decade observations with at least one gold discovery before or after the gold rushes and zero otherwise. Gold Rushes-Not Gold Rushes-(10-20 Years Later) and Gold Rushes-Not Gold Rushes- (20-30 Years Later) equal one for county-decade observations with respectively at least one non-gold rush discovery 10-20 years earlier and 20-30 years earlier. Standard errors clustered by state are reported between parentheses. Columns 1-4 include county and year fixed effects. 
Table A2: Gold Rushes and Notable Places of Worship: Robustness Checks

\begin{tabular}{lccccc}
\hline Probit & \multicolumn{5}{c}{ Place of Worship at the Moment of Gold Discovery } \\
& $(1)$ & $(2)$ & $(3)$ & $(4)$ & $(5)$ \\
\hline Gold Rushes & -0.332 & -0.327 & -0.334 & -0.336 & -0.331 \\
& $(0.107)$ & $(0.112)$ & $(0.124)$ & $(0.127)$ & $(0.116)$ \\
Other Minerals & & & & & \\
& 0.024 & & & 0.025 & \\
& $(0.037)$ & & & $(0.041)$ & \\
$\ln$ (population) & Yes & Yes & Yes & Yes & Yes \\
State FE & Yes & Yes & Yes & Yes & Yes \\
Exogenous controls & Yes & Yes & Yes & Yes & Yes \\
\% of Foreign Born & No & Yes & No & Yes & No \\
Military Base & No & No & Yes & Yes & No \\
Observations & 279 & 279 & 279 & 279 & 216 \\
Pseudo R-Squared & 0.310 & 0.311 & 0.311 & 0.312 & 0.299 \\
\hline \hline
\end{tabular}

Notes: The unit of observation is a county. The sample is restricted to counties with at least one gold discovery at any time. The dependent variable is a dummy which equals one if a notable place of worship existed at the time of gold discovery and zero otherwise. Gold Rushes equals one for counties with at least one gold discovery during the gold rushes and zero otherwise. Marginal effects are reported. Standard errors clustered by state are reported between parentheses. Columns 1-5 include the (log of) 2010 county population and the following exogenous controls: latitude, longitude, total land area, mean and standard deviation of elevation, distance to the state's capital and a dummy for coastal counties. In column 1, we add a control for other minerals (oil or gas resources, copper, iron, nickel or silver). Column 2 includes a control for the share of foreign born. Column 3 includes a dummy for whether the county is housing a U.S. military base. Column 4 adds indicators for military basis and other minerals simultaneously. Column 5 restricts the sample to the Western region. 
Table A3: Simple Difference: Intensive Margin

\begin{tabular}{lcccccc}
\hline \hline & \multicolumn{5}{c}{ Ln(1 + Unmarried Partner Households Same Sex $)$} \\
& $(1)$ & $(2)$ & $(3)$ & $(4)$ & $(5)$ & $(6)$ \\
\hline Num. Gold Rushes & 0.0081 & 0.0081 & 0.0074 & 0.0053 & 0.0046 & 0.0042 \\
Discoveries & $(0.0027)$ & $(0.0028)$ & $(0.0024)$ & $(0.0022)$ & $(0.0019)$ & $(0.0022)$ \\
& & & & & & \\
Num. Gold (Not Gold & & 0.0000 & -0.0004 & -0.0008 & -0.0008 & -0.0006 \\
Rushes) Discoveries & & $(0.0011)$ & $(0.0011)$ & $(0.0009)$ & $(0.0007)$ & $(0.0012)$ \\
& & & & & & \\
$\ln ($ population $)$ & Yes & Yes & Yes & Yes & Yes & Yes \\
Region FE & No & No & No & Yes & No & No \\
Division FE & No & No & No & No & Yes & No \\
State FE & No & No & No & No & No & Yes \\
Exogenous controls & No & No & Yes & Yes & Yes & Yes \\
$P(\beta \neq \lambda)$ & & 0.088 & 0.001 & 0.008 & 0.002 & 0.001 \\
Observations & 3,128 & 3,128 & 3,128 & 3,128 & 3,128 & 3,128 \\
Adjusted R-Squared & 0.955 & 0.955 & 0.958 & 0.961 & 0.963 & 0.965 \\
\hline \hline
\end{tabular}

Notes: The unit of observation is a county. The dependent variable is the natural $\log$ of one plus the number of unmarried partner households of the same sex in 2010 . Num. Gold Rushes is equal to the number of gold rush discoveries. Num. Gold (Not Gold Rushes) is equal to the number of gold discoveries before or after the gold rushes. Standard errors clustered by state are reported between parentheses. Columns 1-6 include the (log of) 2010 county population. The set of exogenous controls include latitude, longitude, total land area, mean and standard deviation of elevation, distance to the state's capital and a dummy for coastal counties. 
Table A4: Robustness Checks: Definition of the Control Group

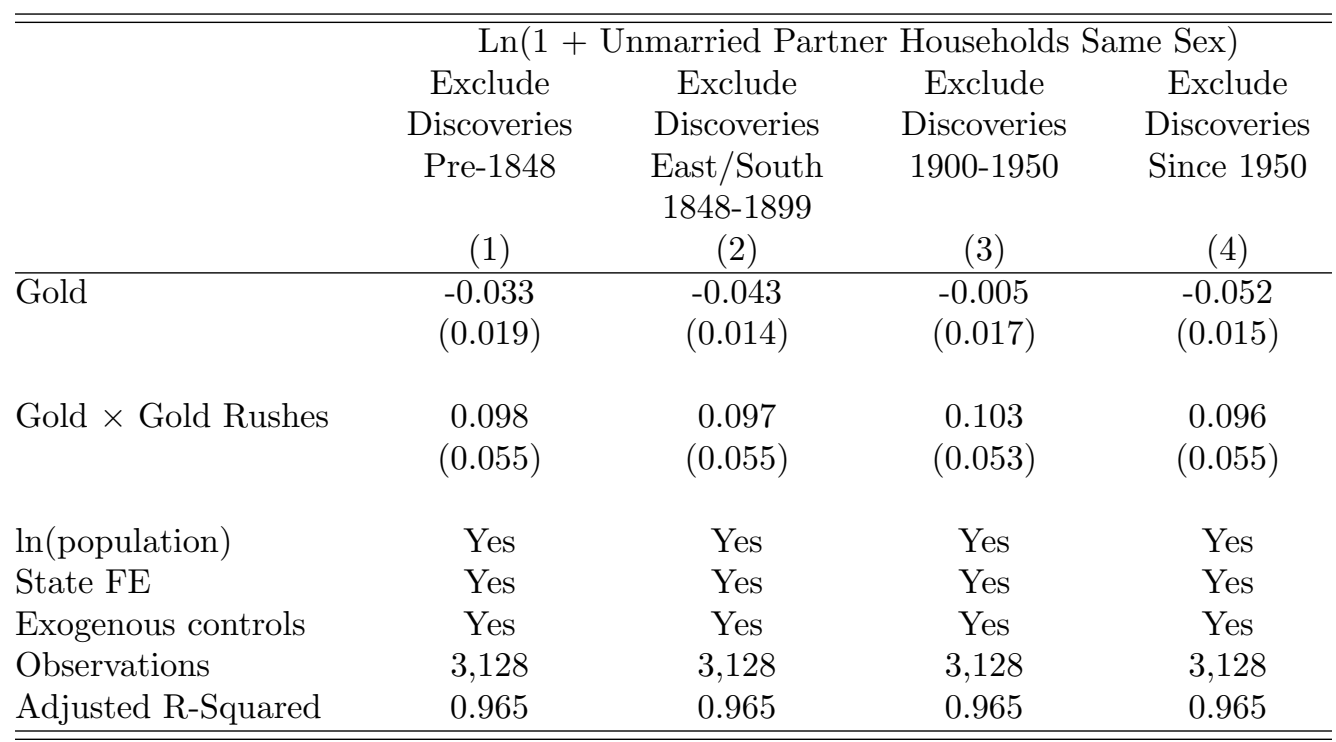

Notes: The unit of observation is a county. The dependent variable is the natural log of one plus the number of unmarried partner households of the same sex in 2010. Gold Rushes equals one for counties with at least one gold discovery during the gold rushes and zero otherwise. Gold equals one for counties with at least one gold discovery and zero otherwise. In column 1, Gold equals zero for gold discoveries before the gold rushes. In column 2, Gold equals zero for gold discoveries during the years 1848-1899, but in the Eastern and Southern regions. In column 3, Gold equals zero for gold discoveries during the years 1900-1950. In column 4, Gold equals zero for gold discoveries since 1950. Standard errors clustered by state are reported between parentheses. Columns 1-6 include the (log of) 2010 county population. The set of exogenous controls include latitude, longitude, total land area, mean and standard deviation of elevation, distance to the state's capital and a dummy for coastal counties. 
Table A5: Simple Difference: Conley's 100-, 300-, and 500-KM Spatial Adjustments

\begin{tabular}{|c|c|c|c|c|c|c|}
\hline & \multicolumn{6}{|c|}{ Ln(1 + Unmarried Partner Households Same Sex) } \\
\hline & Spatial & Spatial & Spatial & Spatial & Spatial & Spatial \\
\hline & $\begin{array}{c}\text { Adjust. } \\
100-\mathrm{km} \\
(1)\end{array}$ & $\begin{array}{c}\text { Adjust. } \\
100-\mathrm{km} \\
(2)\end{array}$ & $\begin{array}{c}\text { Adjust. } \\
300-\mathrm{km} \\
(3)\end{array}$ & $\begin{array}{c}\text { Adjust. } \\
300-\mathrm{km} \\
(4)\end{array}$ & $\begin{array}{c}\text { Adjust. } \\
500-\mathrm{km} \\
(5)\end{array}$ & $\begin{array}{c}\text { Adjust. } \\
500-\mathrm{km} \\
(6)\end{array}$ \\
\hline Gold Rushes & 0.116 & 0.123 & 0.116 & 0.123 & 0.116 & 0.123 \\
\hline$\beta$ & $(0.038)$ & $(0.036)$ & $(0.049)$ & $(0.047)$ & $(0.040)$ & $(0.045)$ \\
\hline Gold (Not Gold Rushes) & -0.052 & -0.042 & -0.052 & -0.042 & -0.052 & -0.042 \\
\hline$\lambda$ & $(0.027)$ & $(0.027)$ & $(0.017)$ & $(0.017)$ & $()$. & $(0.016)$ \\
\hline $\ln$ (population) & Yes & Yes & Yes & Yes & Yes & Yes \\
\hline Division FE & Yes & & Yes & & Yes & \\
\hline State FE & & Yes & & Yes & & Yes \\
\hline Exogenous controls & Yes & Yes & Yes & Yes & Yes & Yes \\
\hline$P(\beta \neq \lambda)$ & 0.0008 & 0.0005 & 0.0011 & 0.0001 & 0.0000 & 0.0003 \\
\hline Observations & 3,128 & 3,128 & 3,128 & 3,128 & 3,128 & 3,128 \\
\hline
\end{tabular}

Notes: The unit of observation is a county. The dependent variable is the natural log of one plus the number of unmarried partner households of the same sex in 2010. Gold Rushes equals one for counties with at least one gold discovery during the gold rushes and zero otherwise. Gold (Not Gold Rushes) equals one for counties with at least one gold discovery before or after the gold rushes and zero otherwise. Standard errors are computed following Conley (1999, 2008) and Hsiang (2010) and using 100-, 300-, and $500-\mathrm{km}$ spatial adjustments. Columns 1-6 include the (log of) 2010 county population and our set of exogenous controls (see Table 4). We add controls for the presence of oil or gas resources, the share of foreign born and a dummy for whether the county is housing a U.S. military base. 
Table A6: Simple Difference: Robustness Checks

\begin{tabular}{|c|c|c|c|c|c|}
\hline & $\operatorname{Ln}($ & Unmarr & Partner & ousehold & (e Sex) \\
\hline & $(1)$ & $(2)$ & $(3)$ & $(4)$ & $(5)$ \\
\hline Gold Rushes & 0.121 & 0.123 & 0.123 & 0.121 & 0.122 \\
\hline$\beta$ & $(0.049)$ & $(0.049)$ & $(0.049)$ & $(0.049)$ & $(0.042)$ \\
\hline Gold (Not Gold Rushes) & -0.046 & -0.042 & -0.042 & -0.046 & -0.040 \\
\hline$\lambda$ & $(0.016)$ & $(0.017)$ & $(0.016)$ & $(0.016)$ & $(0.033)$ \\
\hline Other Minerals & 0.009 & & & 0.009 & \\
\hline & $(0.018)$ & & & $(0.018)$ & \\
\hline $\ln$ (population) & Yes & Yes & Yes & Yes & Yes \\
\hline State FE & Yes & Yes & Yes & Yes & Yes \\
\hline Exogenous controls & Yes & Yes & Yes & Yes & Yes \\
\hline$\%$ of Foreign Born & No & Yes & No & Yes & No \\
\hline Military Base & No & No & Yes & Yes & No \\
\hline$P(\beta \neq \lambda)$ & 0.001 & 0.001 & 0.001 & 0.001 & 0.003 \\
\hline Observations & 3,128 & 3,128 & 3,128 & 3,128 & 434 \\
\hline Adjusted R-Squared & 0.965 & 0.965 & 0.965 & 0.965 & 0.965 \\
\hline
\end{tabular}

Notes: The unit of observation is a county. The dependent variable is the natural log of one plus the number of unmarried partner households of the same sex in 2010 . Gold Rushes equals one for counties with at least one gold discovery during the gold rushes and zero otherwise. Gold (Not Gold Rushes) equals one for counties with at least one gold discovery before or after the gold rushes and zero otherwise. Standard errors clustered by state are reported between parentheses. Columns 1-6 include the (log of) 2010 county population and our set of exogenous controls (see Table 4). In column 1, we add a control for other minerals (oil or gas resources, copper, iron, nickel or silver). Column 2 includes a control for the share of foreign born. Column 3 includes a dummy for whether the county is housing a U.S. military base. 
Table A7: Differences-in-Differences: Same-Sex Married Couples

\begin{tabular}{|c|c|c|c|c|c|c|}
\hline & & $\operatorname{Ln}(1$ & Same-Se & Married & uples) & \\
\hline & (1) & $(2)$ & (3) & $(4)$ & $(5)$ & (6) \\
\hline Gold & $\begin{array}{c}0.191 \\
(0.081)\end{array}$ & $\begin{array}{c}0.118 \\
(0.079)\end{array}$ & $\begin{array}{c}0.156 \\
(0.059)\end{array}$ & $\begin{array}{c}0.112 \\
(0.059)\end{array}$ & $\begin{array}{c}0.036 \\
(0.059)\end{array}$ & $\begin{array}{c}0.115 \\
(0.056)\end{array}$ \\
\hline Gold $\times$ Gold Rushes & & $\begin{array}{c}0.218 \\
(0.090)\end{array}$ & $\begin{array}{c}0.333 \\
(0.117)\end{array}$ & $\begin{array}{c}0.046 \\
(0.078)\end{array}$ & $\begin{array}{c}0.076 \\
(0.081)\end{array}$ & $\begin{array}{c}0.106 \\
(0.070)\end{array}$ \\
\hline $\ln$ (population) & Yes & Yes & Yes & Yes & Yes & Yes \\
\hline Region FE & No & No & No & Yes & No & No \\
\hline Division FE & No & No & No & No & Yes & No \\
\hline State FE & No & No & No & No & No & Yes \\
\hline Exogenous controls & No & No & Yes & Yes & Yes & Yes \\
\hline Observations & 2,346 & 2,346 & 2,346 & 2,346 & 2,346 & 2,346 \\
\hline Adjusted R-Squared & 0.057 & 0.057 & 0.089 & 0.125 & 0.143 & 0.184 \\
\hline
\end{tabular}

Notes: The unit of observation is a PUMA. The dependent variable is the natural log of one plus the number of same-sex married couples. The time period is 2013-2016. Gold Rushes equals one for PUMAs with at least one gold discovery during the gold rushes and zero otherwise. Gold equals one for PUMAs with at least one gold discovery and zero otherwise. Standard errors clustered by state are reported between parentheses. Columns 1-6 include the (log of) 2010 county population. The set of exogenous controls include latitude, longitude, total land area, mean and standard deviation of elevation, distance to the state's capital and a dummy for coastal counties. 
Table A8: Simple Difference: Socioeconomic Characteristics

\begin{tabular}{lcccccc}
\hline \hline & \multicolumn{6}{c}{$\operatorname{Ln}(1+\mathrm{Unm}$ Urried Partner Households Same Sex) } \\
& $(1)$ & $(2)$ & $(3)$ & $(4)$ & $(5)$ & $(6)$ \\
\hline Gold Rushes & 0.124 & 0.124 & 0.120 & 0.113 & 0.119 & 0.092 \\
$\beta$ & $(0.050)$ & $(0.050)$ & $(0.044)$ & $(0.036)$ & $(0.044)$ & $(0.034)$ \\
& & & & & & \\
Gold (Not Gold Rushes) & -0.054 & -0.051 & -0.040 & -0.061 & -0.053 & -0.048 \\
$\lambda$ & $(0.017)$ & $(0.016)$ & $(0.016)$ & $(0.018)$ & $(0.018)$ & $(0.019)$
\end{tabular}

Additional Controls

Demographic Mechanism:

$\%$ Black or African American

Fractionalization Index

Economic Mechanism:

Median Personal Income

Poverty Rate

Unemployment rate

Urban Mechanism:

Median House Value

$\%$ House Less $\$ 100 \mathrm{~K}$

$\%$ House More $\$ 500 \mathrm{~K}$

$\%$ Urban

Population Density

Education Mechanism:

$\%$ High School Graduate

$\ln$ (population)

State FE

Exogenous controls

Other Minerals

$\%$ of Foreign Born

Military Base

$P(\beta \neq \lambda)$

Observations

Adjusted R-Squared
Yes

Yes

Yes

Yes

$\begin{array}{lc}\text { Yes } & \text { Yes } \\ \text { Yes } & \text { Yes } \\ \text { Yes } & \text { Yes }\end{array}$

Notes: The unit of observation is a county. The dependent variable is the natural $\log$ of one plus the number of unmarried partner households of the same sex in 2010 . Gold Rushes equals one for counties with at least one gold discovery during the gold rushes and zero otherwise. Gold (Not Gold Rushes) equals one for counties with at least one gold discovery before or after the gold rushes and zero otherwise. Standard errors clustered by state are reported between parentheses. Columns 1-6 include the (log of) 2010 county population. The set of exogenous controls include latitude, longitude, total land area, mean and standard deviation of elevation, distance to the state's capital and a dummy for coastal counties. We also control for other minerals (oil or gas resources, copper, iron, nickel or silver), the share of foreign born and for whether the county is housing a U.S. military base. 
Table A9: Socioeconomic Covariates

\begin{tabular}{|c|c|c|c|c|}
\hline & \multicolumn{4}{|c|}{ Ln(1 + Unmarried Partner HH Same Sex $)$} \\
\hline & $(1)$ & $(2)$ & (3) & (4) \\
\hline \% Black or African American & $\begin{array}{l}-0.039 \\
(0.090)\end{array}$ & & & \\
\hline Fractionalization Index & $\begin{array}{c}0.201 \\
(0.122)\end{array}$ & & & \\
\hline $\ln$ (Median Personal Income) & & $\begin{array}{c}0.332 \\
(0.062)\end{array}$ & & \\
\hline Poverty Rate & & $\begin{array}{c}0.004 \\
(0.003)\end{array}$ & & \\
\hline Unemployment rate & & $\begin{array}{c}0.003 \\
(0.005)\end{array}$ & & \\
\hline $\ln$ (Median House Value) & & & $\begin{array}{c}0.198 \\
(0.036)\end{array}$ & \\
\hline$\%$ House Value Less $\$ 100 \mathrm{~K}$ & & & Omitted & \\
\hline$\%$ House Value More $\$ 500 \mathrm{~K}$ & & & Omitted & \\
\hline$\%$ Urban & & & $\begin{array}{c}-0.0014 \\
(0.0003)\end{array}$ & \\
\hline Population Density & & & Omitted & \\
\hline \% High School Graduate & & & & $\begin{array}{c}0.011 \\
(0.003)\end{array}$ \\
\hline $\ln ($ population $)$ & Yes & Yes & Yes & Yes \\
\hline State FE & Yes & Yes & Yes & Yes \\
\hline Exogenous controls & Yes & Yes & Yes & Yes \\
\hline Other Minerals & Yes & Yes & Yes & Yes \\
\hline$\%$ of Foreign Born & Yes & Yes & Yes & Yes \\
\hline Military Base & Yes & Yes & Yes & Yes \\
\hline Observations & 3,070 & 3,070 & 3,070 & 3,070 \\
\hline
\end{tabular}


Table A10: Attitudes Toward LGBT: Socioeconomic Covariates

\begin{tabular}{|c|c|c|c|}
\hline & Sex & en Two Ac & Same Sex \\
\hline & (1) & $(2)$ & (3) \\
\hline Male & -0.209 & -0.211 & -0.212 \\
\hline & $(0.022)$ & $(0.022)$ & $(0.022)$ \\
\hline Age & 0.005 & 0.003 & 0.004 \\
\hline & $(0.004)$ & $(0.004)$ & $(0.004)$ \\
\hline Age Squared & -0.015 & -0.014 & -0.016 \\
\hline & $(0.004)$ & $(0.004)$ & $(0.004)$ \\
\hline Elementary School & -0.992 & -0.963 & -0.945 \\
\hline & $(0.062)$ & $(0.060)$ & $(0.067)$ \\
\hline Attended High School & -0.846 & -0.822 & -0.799 \\
\hline & $(0.041)$ & $(0.041)$ & $(0.041)$ \\
\hline Grad. High School & -0.663 & -0.653 & -0.637 \\
\hline & $(0.042)$ & $(0.042)$ & $(0.039)$ \\
\hline Attended College & -0.446 & -0.440 & -0.430 \\
\hline & $(0.041)$ & $(0.040)$ & $(0.039)$ \\
\hline College & -0.181 & -0.180 & -0.179 \\
\hline & $(0.043)$ & $(0.043)$ & $(0.044)$ \\
\hline Post Graduate & Omitted & Omitted & Omitted \\
\hline White & 0.170 & 0.216 & 0.245 \\
\hline & $(0.057)$ & $(0.049)$ & $(0.050)$ \\
\hline Black or African American & -0.383 & -0.289 & -0.262 \\
\hline & $(0.057)$ & $(0.056)$ & $(0.058)$ \\
\hline Other Race & Omitted & Omitted & Omitted \\
\hline Married & Omitted & Omitted & Omitted \\
\hline Widow & 0.097 & 0.087 & 0.095 \\
\hline & $(0.039)$ & $(0.039)$ & $(0.040)$ \\
\hline Separated & 0.297 & 0.284 & 0.271 \\
\hline & $(0.061)$ & $(0.063)$ & $(0.060)$ \\
\hline Divorced & 0.293 & 0.304 & 0.304 \\
\hline & $(0.035)$ & $(0.036)$ & $(0.036)$ \\
\hline Never Married & 0.489 & 0.466 & 0.457 \\
\hline & $(0.029)$ & $(0.029)$ & $(0.029)$ \\
\hline Division FE & & Yes & \\
\hline State FE & & & Yes \\
\hline Exogenous controls & Yes & Yes & Yes \\
\hline Observations & 16,084 & 16,084 & 16,084 \\
\hline Pseudo R-Squared & 0.082 & 0.090 & 0.098 \\
\hline
\end{tabular}

Notes: The unit of observation is a respondent. The period covered is 1993-2014. Attitudes toward LGBT is assessed through the following question: "What about sexual relations between two adults of the same sex-do you think it is" where respondents have four choices $(4=$ not wrong at all, $3=$ wrong only sometimes, $2=$ almost always wrong and $1=$ always wrong). Standard errors clustered by state are reported between parentheses. The set of exogenous controls include latitude, longitude, total land area, mean and standard deviation of elevation, distance to the state's capital and a dummy for coastal counties. 
Table A11: Attitudes Toward LGBT: Geographic Mobility

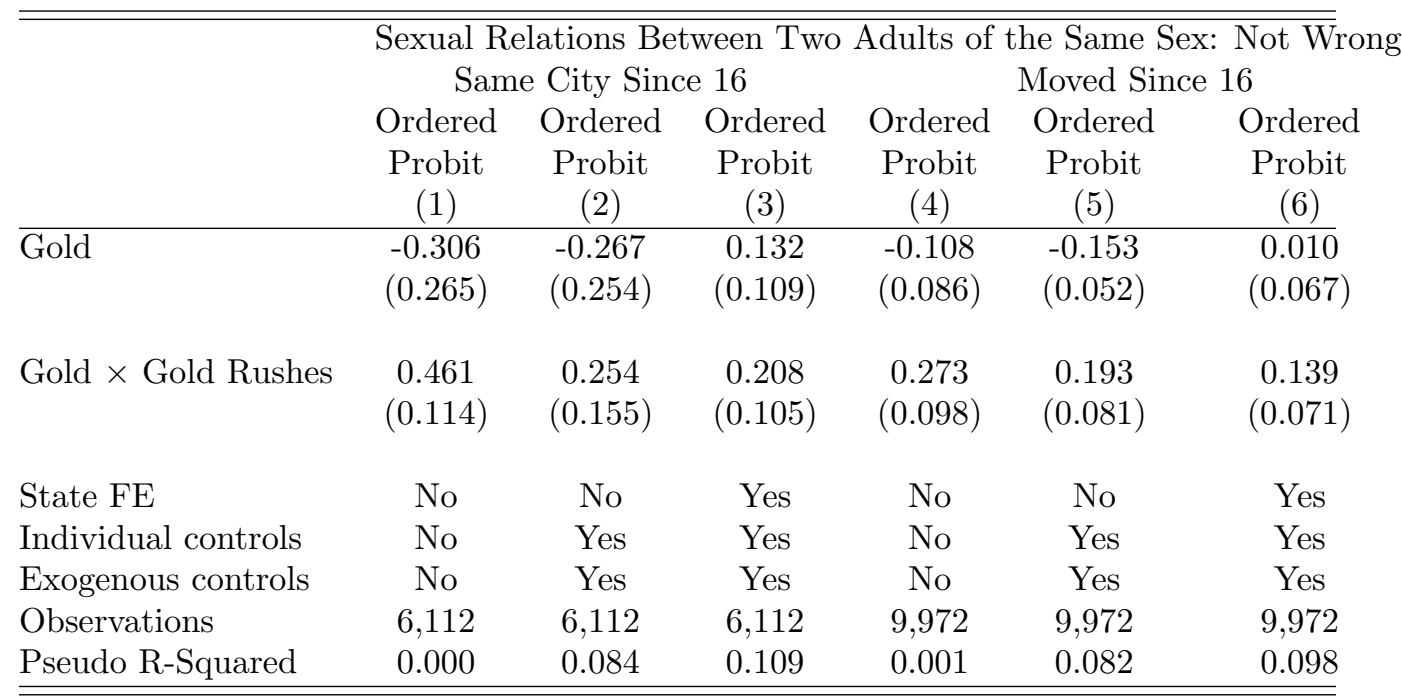

Notes: The unit of observation is a respondent. The period covered is 1993-2014. Attitudes toward LGBT is assessed through the following question: "What about sexual relations between two adults of the same sex-do you think it is" where respondents have four choices $(4=$ not wrong at all, $3=$ wrong only sometimes, $2=$ almost always wrong and $1=$ always wrong). Columns $1-3$ restrict the sample to respondents who are living in the same city since age 16 . Columns $4-6$ restrict the sample to individuals who moved to a different city or state since the age of 16 . Gold equals one for counties with at least one gold discovery and zero otherwise. Gold Rushes equals one for counties with at least one gold discovery during the gold rushes and zero otherwise. Standard errors clustered by state are reported between parentheses. The set of exogenous controls include latitude, longitude, total land area, mean and standard deviation of elevation, distance to the state's capital and a dummy for coastal counties. The set of individual controls include the following variables: gender, age, age squared, six education dummies, three race dummies and five marital status dummies. 
Table A12: Attitudes Toward LGBT: Pro-LGBT Index

\begin{tabular}{lcccccc}
\hline \hline & & \multicolumn{5}{c}{ Pro-LGBT Index } \\
& $\begin{array}{c}\text { Ordered } \\
\text { Probit } \\
(1)\end{array}$ & $\begin{array}{c}\text { Ordered } \\
\text { Probit } \\
(2)\end{array}$ & $\begin{array}{c}\text { Ordered } \\
\text { Probit } \\
(3)\end{array}$ & $\begin{array}{c}\text { Ordered } \\
\text { Probit } \\
(4)\end{array}$ & $\begin{array}{c}\text { Ordered } \\
\text { Probit } \\
(5)\end{array}$ & $\begin{array}{c}\text { Ordered } \\
\text { Probit } \\
(6)\end{array}$ \\
\hline Gold & 0.172 & -0.170 & -0.224 & -0.217 & -0.128 & 0.002 \\
& $(0.099)$ & $(0.130)$ & $(0.108)$ & $(0.053)$ & $(0.058)$ & $(0.083)$ \\
Gold $\times$ Gold Rushes & & 0.326 & 0.251 & 0.165 & 0.131 & 0.108 \\
& & $(0.091)$ & $(0.075)$ & $(0.082)$ & $(0.077)$ & $(0.079)$ \\
Division FE & No & No & No & No & Yes & No \\
State FE & No & No & No & No & No & Yes \\
Individual controls & No & No & Yes & Yes & Yes & Yes \\
Exogenous controls & No & No & No & Yes & Yes & Yes \\
Observations & 15,359 & 15,359 & 15,359 & 15,359 & 15,359 & 15,359 \\
Adjusted R-Squared & 0.001 & 0.004 & 0.066 & 0.073 & 0.079 & 0.086 \\
\hline \hline
\end{tabular}

Notes: The unit of observation is a respondent. The period covered is 1993-2014. We use answers to the following four questions to create a pro-LGBT index: "What about sexual relations between two adults of the same sex-do you think it is, not wrong at all, wrong only sometimes, almost always wrong and always wrong?", "A man admits to be homosexual: should he be allowed to make a speech in your community?", "A man admits to be homosexual: should he be allowed to teach in a college or university?" and "If some people in your community suggested that a book he wrote in favor of homosexuality, should it be taken out of your public library?" The index goes from 0 to 4 . Gold equals one for counties with at least one gold discovery and zero otherwise. Gold Rushes equals one for counties with at least one gold discovery during the gold rushes and zero otherwise. Standard errors clustered by state are reported between parentheses. The set of exogenous controls include latitude, longitude, total land area, mean and standard deviation of elevation, distance to the state's capital and a dummy for coastal counties. The set of individual controls include the following variables: gender, age, age squared, six education dummies, three race dummies and five marital status dummies. 
Table A13: Praying: GSS

\begin{tabular}{lcccccc}
\hline \hline & \multicolumn{5}{c}{ Respondent Reports Never Praying } \\
& Probit & Probit & Probit & Probit & Probit & Probit \\
& $(1)$ & $(2)$ & $(3)$ & $(4)$ & $(5)$ & $(6)$ \\
\hline Gold & 0.186 & -0.181 & -0.185 & -0.164 & -0.059 & 0.057 \\
& $(0.067)$ & $(0.158)$ & $(0.151)$ & $(0.123)$ & $(0.148)$ & $(0.116)$ \\
& & & & & & \\
Gold $\times$ Gold Rushes & & 0.287 & 0.219 & 0.207 & 0.157 & 0.187 \\
& & $(0.062)$ & $(0.060)$ & $(0.101)$ & $(0.087)$ & $(0.091)$ \\
Division FE & No & No & No & No & Yes & No \\
State FE & No & No & No & No & No & Yes \\
Individual controls & No & No & Yes & Yes & Yes & Yes \\
Exogenous controls & No & No & No & Yes & Yes & Yes \\
Observations & 19,724 & 19,724 & 19,724 & 19,724 & 19,724 & 19,546 \\
Pseudo R-Squared & 0.003 & 0.006 & 0.084 & 0.089 & 0.099 & 0.113 \\
\hline \hline
\end{tabular}

Notes: The unit of observation is a respondent. The period covered is 1993-2014. The dependent variable is a dummy for whether the respondent reports never praying. This is assessed through the following question: "How often does r pray?" Gold equals one for counties with at least one gold discovery and zero otherwise. Gold Rushes equals one for counties with at least one gold discovery during the gold rushes and zero otherwise. Standard errors clustered by state are reported between parentheses. The set of exogenous controls include latitude, longitude, total land area, mean and standard deviation of elevation, distance to the state's capital and a dummy for coastal counties. The set of individual controls include the following variables: gender, age, age squared, six education dummies, three race dummies and five marital status dummies. 
Table A14: Other Attitudes and Values: GSS

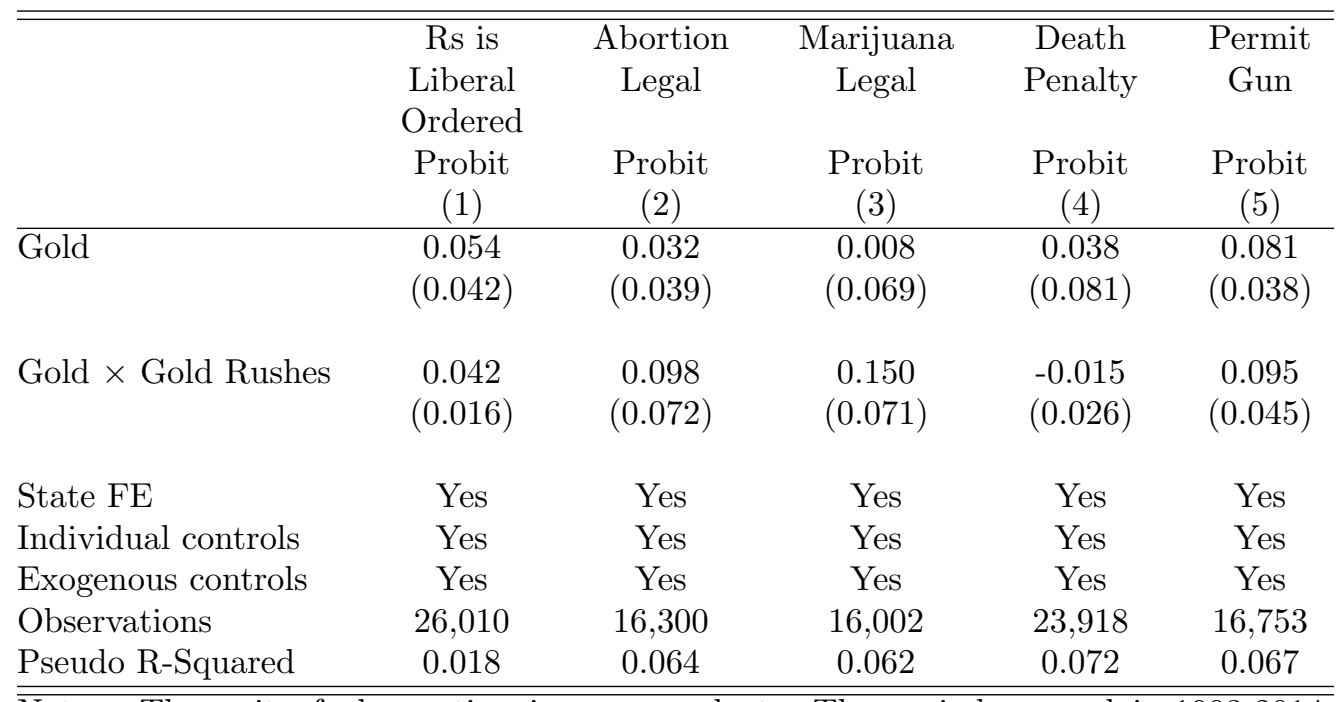

Notes: The unit of observation is a respondent. The period covered is 1993-2014. In column 1, the dependent variable is whether respondents think of themselves as liberal or conservative. Respondents are offered seven choices $(7=$ extremely liberal, 6 =liberal, $5=$ slightly liberal, $4=$ moderate, $3=$ slightly conservative, $2=$ conservative and $1=$ extremely conservative). In columns $2-5$, the dependent variables are answers to the following questions "Please tell me whether or not you think it should be possible for a pregnant woman to obtain a legal abortion if she is married and does not want any more children", "Do you think the use of marijuana should be made legal or not?", "Do you favor or oppose the death penalty for persons convicted of murder?" and "Would you favor or oppose a law which would require a person to obtain a police permit before he or she could buy a gun?" Gold equals one for counties with at least one gold discovery and zero otherwise. Gold Rushes equals one for counties with at least one gold discovery during the gold rushes and zero otherwise. Standard errors clustered by state are reported between parentheses. The set of exogenous controls include latitude, longitude, total land area, mean and standard deviation of elevation, distance to the state's capital and a dummy for coastal counties. The set of individual controls include the following variables: gender, age, age squared, six education dummies, three race dummies and five marital status dummies. 
Table A15: Instrumental Variable: Maximum Male-to-Female Ratio

\begin{tabular}{|c|c|c|c|c|c|c|}
\hline \multicolumn{7}{|l|}{ Panel A: First stage } \\
\hline & (1) & (2) & (3) & (4) & $(5)$ & (6) \\
\hline Gold Rushes & & & & $\begin{array}{c}0.619 \\
(0.153)\end{array}$ & $\begin{array}{c}0.274 \\
(0.089)\end{array}$ & $\begin{array}{c}0.271 \\
(0.086)\end{array}$ \\
\hline Kleibergen-Paap F-statistic & & & & 16.39 & 9.45 & 9.90 \\
\hline \multicolumn{7}{|l|}{ Panel B: Second stage } \\
\hline ln(Max Male-to-Female Ratio) & $\begin{array}{c}(1) \\
-0.025 \\
(0.034)\end{array}$ & $\begin{array}{c}(2) \\
-0.026 \\
(0.020)\end{array}$ & $\begin{array}{c}(3) \\
-0.026 \\
(0.021)\end{array}$ & $\begin{array}{c}(4) \\
0.216 \\
(0.113)\end{array}$ & $\begin{array}{c}(5) \\
0.448 \\
(0.299)\end{array}$ & $\begin{array}{c}(6) \\
0.452 \\
(0.298)\end{array}$ \\
\hline $\ln ($ population $)$ & Yes & Yes & Yes & Yes & Yes & Yes \\
\hline State FE & No & No & Yes & No & No & Yes \\
\hline Exogenous controls & No & Yes & Yes & No & Yes & Yes \\
\hline$\%$ of Foreign Born & No & No & Yes & No & No & Yes \\
\hline Military Base & No & No & Yes & No & No & Yes \\
\hline Observations & 3,128 & 3,128 & 3,128 & 3,128 & 3,128 & 3,128 \\
\hline Adjusted R-Squared & 0.955 & 0.965 & 0.965 & 0.952 & 0.956 & 0.956 \\
\hline
\end{tabular}

Notes: The unit of observation is a county. In panel $\mathrm{A}$, the dependent variable is the natural $\log$ of the maximum male-to-female ratio. The instrumental variable is the variable Gold Rushes. Gold Rushes equals one for counties with at least one gold discovery during the gold rushes and zero otherwise. We present 2SLS estimates in panel B. The dependent variable is the natural log of one plus the number of unmarried partner households of the same sex in 2010. Standard errors clustered by state are reported between parentheses. Columns 1-6 include the (log of) 2010 county population. The set of exogenous controls include latitude, longitude, total land area, mean and standard deviation of elevation, distance to the state's capital and a dummy for coastal counties. In columns 3 and 6 , we add controls the share of foreign born and a dummy for whether the county is housing a U.S. military base. 